\title{
Prácticas usuales y nuevas urgencias para una agenda de la promoción de la lectura
}

Gustavo Bombini

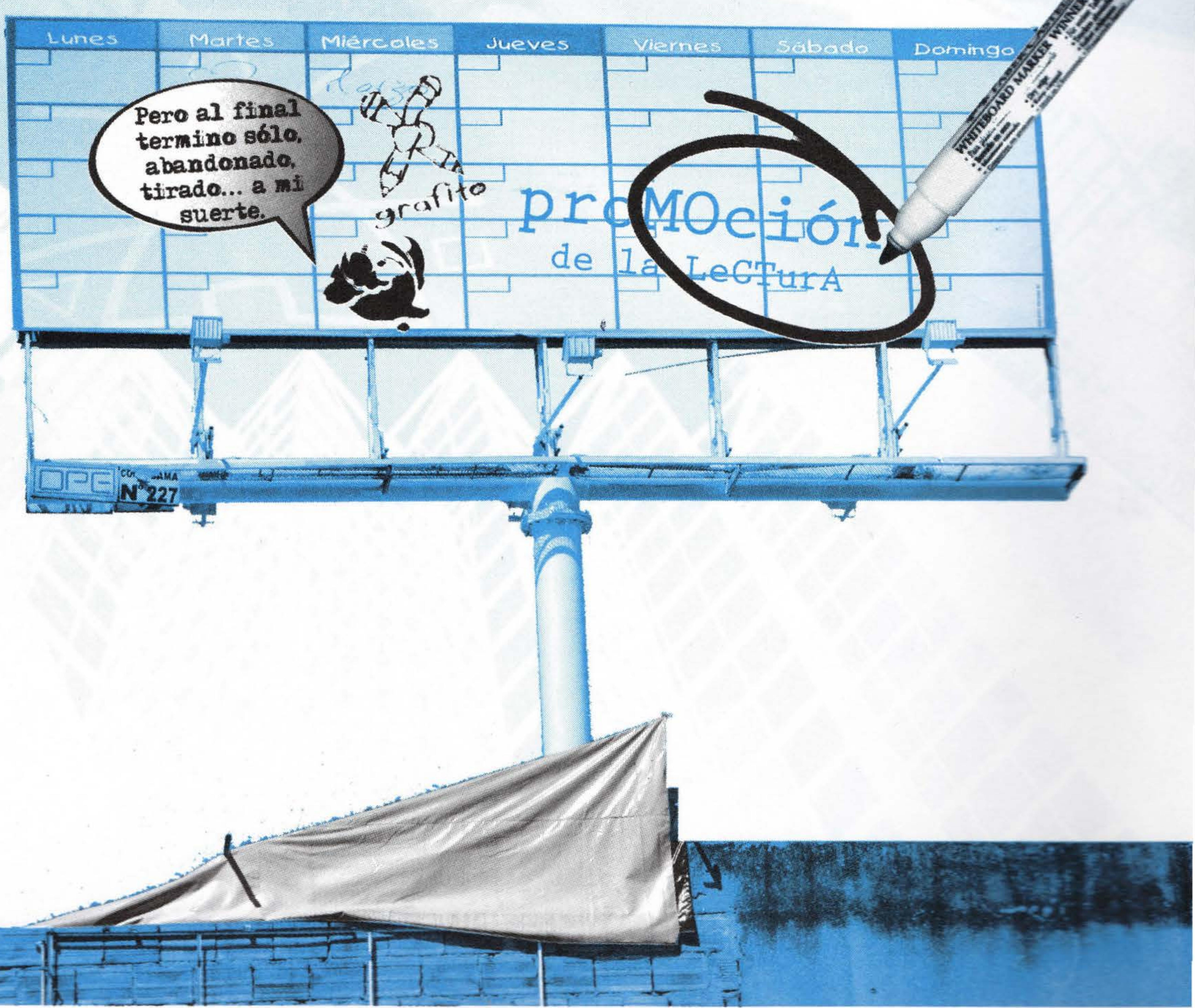


Gustavo Bombini es Doctor en Letras, titular de la cátedra de Didáctica en Letras de la Universidad Nacional de La Plata; docente investigador de la misma cátedra en la Universidad Nacional de Buenos Aires y autor de los libros La trama de los textos, Otras tramas y El nuevo Escriturón. También forma parte del consejo de redacción de las revistas Versiones y La Mancha; es director de la editorial El Hacedor y vicepresidente de A.L.I.J.A. Correo electrónico: gbombini@gmail.com

\section{Resumen}

Se describen y analizan algunas cuestiones que hacen a la construcción y puesta en práctica de políticas públicas de promoción de la lectura desarrolladas en el ámbito estatal, con cierto acento inevitable puesto en las particularidades que este tipo de prácticas asume en los países de la región latinoamericana. Referirse a la construcción de políticas públicas de lectura no supone dar cuenta solo de aspectos específicamente técnico-políticos vinculados con la gestión, la planificación y la evaluación de este tipo de acciones sino también de poner de relieve algunas dimensiones culturales, téoricas, pedagógicas y metodológicas que deben ser el presupuesto de trabajo de los aspectos antes mencionados. Se podría sostener que sobre la vieja agenda que prioriza la lectura y los planes de acción en pro de su promoción, se vuelve necesario discutir aspectos más generales de marco que nos permitan realizar una reconsideración del sentido de estas prácticas, de la definición de su especificidad y de sus posibles horizontes de impacto.

\section{Palabras claves: Políticas públicas, promoción de la lectura}

\section{Abstract}

The article refers to some questions that contribute to the construction and development of public policies concerning reading promotion with emphasis on the issues of the Latin American region. Public policies on reading imply not only the account of technical and political issues but also stressing on the cultural, theoretical, pedagogical and methodological dimmensions as previous references. It is urgently needed to analyze and discuss general aspects in order to reconsider the scope of these practices and their possible impact.

\section{Key Words: Public policy, Reading promotion}




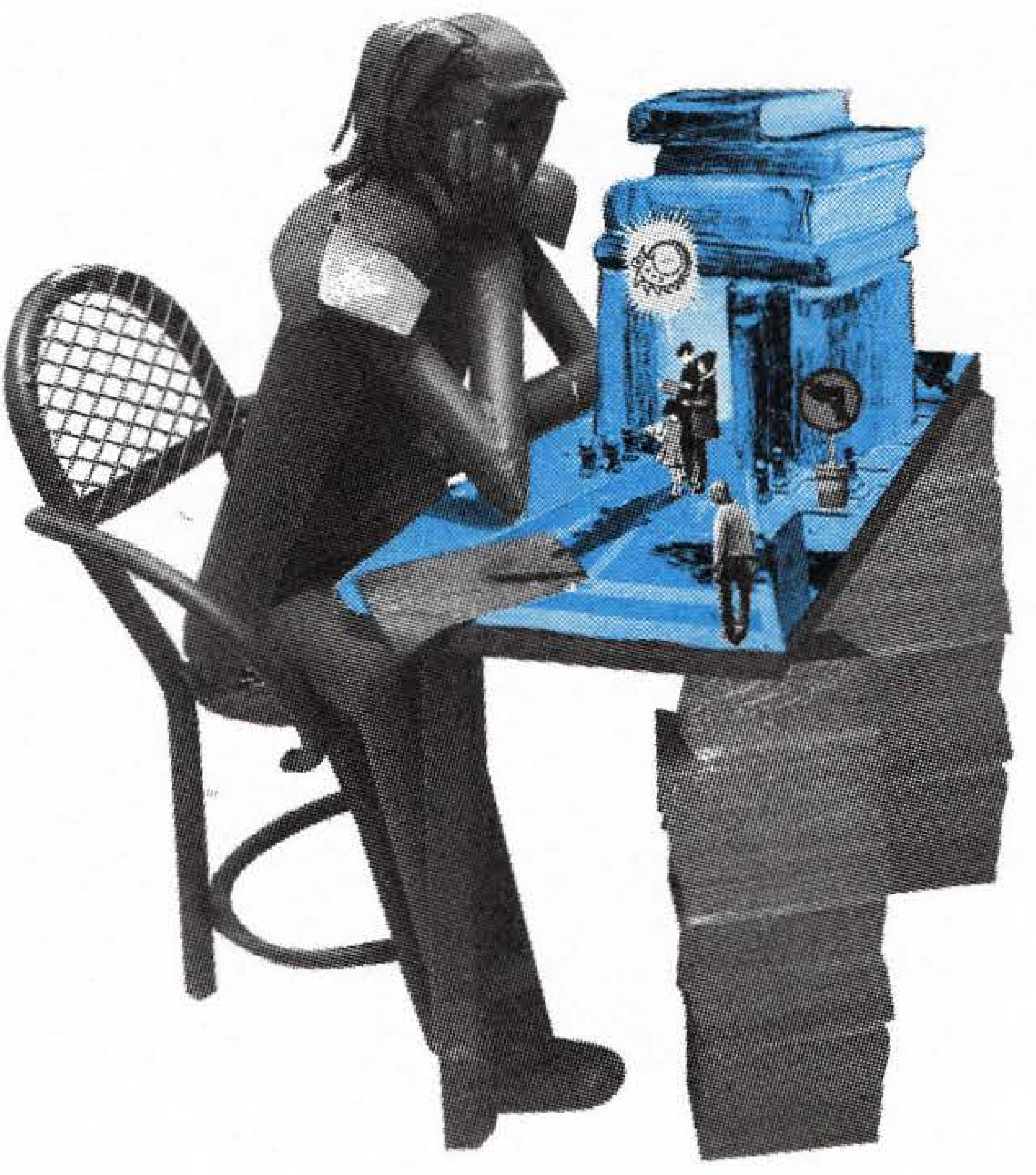

Un punto de partida posible sería el de determinar qué experiencias, prácticas o proyectos quedan englobadas dentro de este campo cultural y educativo que es el campo de la promoción de la lectura pues a partir de esa diversidad podríamos dar cuenta de algunos de los problemas que nos plantea definir este campo como campo de acción y de reflexión. Lectura y promoción son términos que parecen recubrir diversidad de prácticas: desde una visita de un promotor editorial a una biblioteca escolar hasta un programa de alto alcance de desarrollo curricular de un organismo educativo gubernamental. Promover la lectura es hacer una recomendación de lectura a un grupo de taller literario o desplegar un proyecto editorial de gran cobertura tendiente a dotar de nuevos materiales a las bibliotecas públicas de una escuela; es escribir el guión de un corto publicitario para la televisión u organizar una maratón para premiar al niño que lee más libros de una escuela.
Desearíamos quebrar una lógica doblemente improductiva que va de la metáfora atractiva y biensonante pero excluyente al dato cuantitativo que alarma y paraliza. ¿Cómo salir de la lógica circular? ¿Cambiar los instrumentos de medición o cambiar las metáforas?

Entre un margen lábil, por momentos o claramente delimitado por otros, borroso a veces o atravesado por tensiones y contradicciones, "promoción de la lectura" se dice de gran cantidad de prácticas y esto plantea un primer desafío epistemológico y metodológico y acaso un segundo a la hora de definir políticas de acción en este sector. 
Quienes venimos trabajando en este campo desde distintos espacios institucionales, estatales y de la sociedad civil, privados y públicos, escolares y de otras modalidades de la educación, advertimos estas tensiones, nos hacemos cargo de estas diferencias y trabajamos en la construcción de una agenda cada vez más minuciosa y discriminada que sin excluir ninguna dimensión, nos permita ser concientes de qué hablamos cada vez que hablamos de promoción de la lectura. El inicio de esta construcción es necesariamente teórica e involucra a la propia definición de lectura -implícita o explícita- que subyacen a las prácticas, a los supuestos y representaciones sociales sobre la lectura, a los modos de apropiación de la cultura escrita propios de los distintos grupos, a las tradiciones y habitus que conforman el punto de partida de toda práctica social. En cada caso, sean quienes sean los que leen (los niños, los adultos, los que no tiene empleo, los inmigrantes, los jubilados, etc.), con los propósitos que lo hagan (para aprender, para informarse, para entretenerse, para encontrarle otro sentido a la vida), en el ámbito en que desarrollen su práctica (la biblioteca, la escuela, el centro cultural, la cárcel), en los tiempos en que sea posible (un tiempo programado, un tiempo de espera, un tiempo robado a otro, un tiempo clandestino e inconfesado), cada una de estas variables entrecruzadas en sus posibles combinaciones dará cuenta de infinitas escenas de lectura que tendrán en su particularísimos rasgos y características un especialísimo interés. Veremos cómo estos modos de entender la lectura tendrán un respaldo teórico y metodológico que nos permitirá avanzar en un mayor conocimiento acerca de qué entendemos por lectura.
Planteada la lectura como una práctica cultural que asume características y formatos variados y que puede ser considerada desde las más diversas perspectivas cabe preguntarse qué tipo de decisiones de recorte serán pasibles de ser tomadas para la construcción de una política de estado. A la hora de planificar una política pública de lectura -y en nuestro caso particular- desde un Ministerio de Educación Nacional- nos preguntamos qué lecturas, qué prácticas, con qué sujetos, con qué estrategias, según qué concepciones formarán parte del programa de acción oficial a desarrollar.

Acaso un primer paso para imaginar esas operaciones de recorte sea analizar en qué contexto político, socioeconómico, cultural, educativo se deciden y se llevan adelante líneas de acción. ¿Cuál es el estado de las cosas en el momento en que los Estados -y hoy en día los Estados de Iberoamérica en torno a Ilímita y con apoyo de la OEI (Organización de los Estados Iberoamericanos) avanzan en la consolidación de redes de intercambio y proyectos conjuntos entre países)- deciden privilegiar, a través de sus ministerios de educación y de cultura, planes, programas y proyectos de promoción de la lectura? 


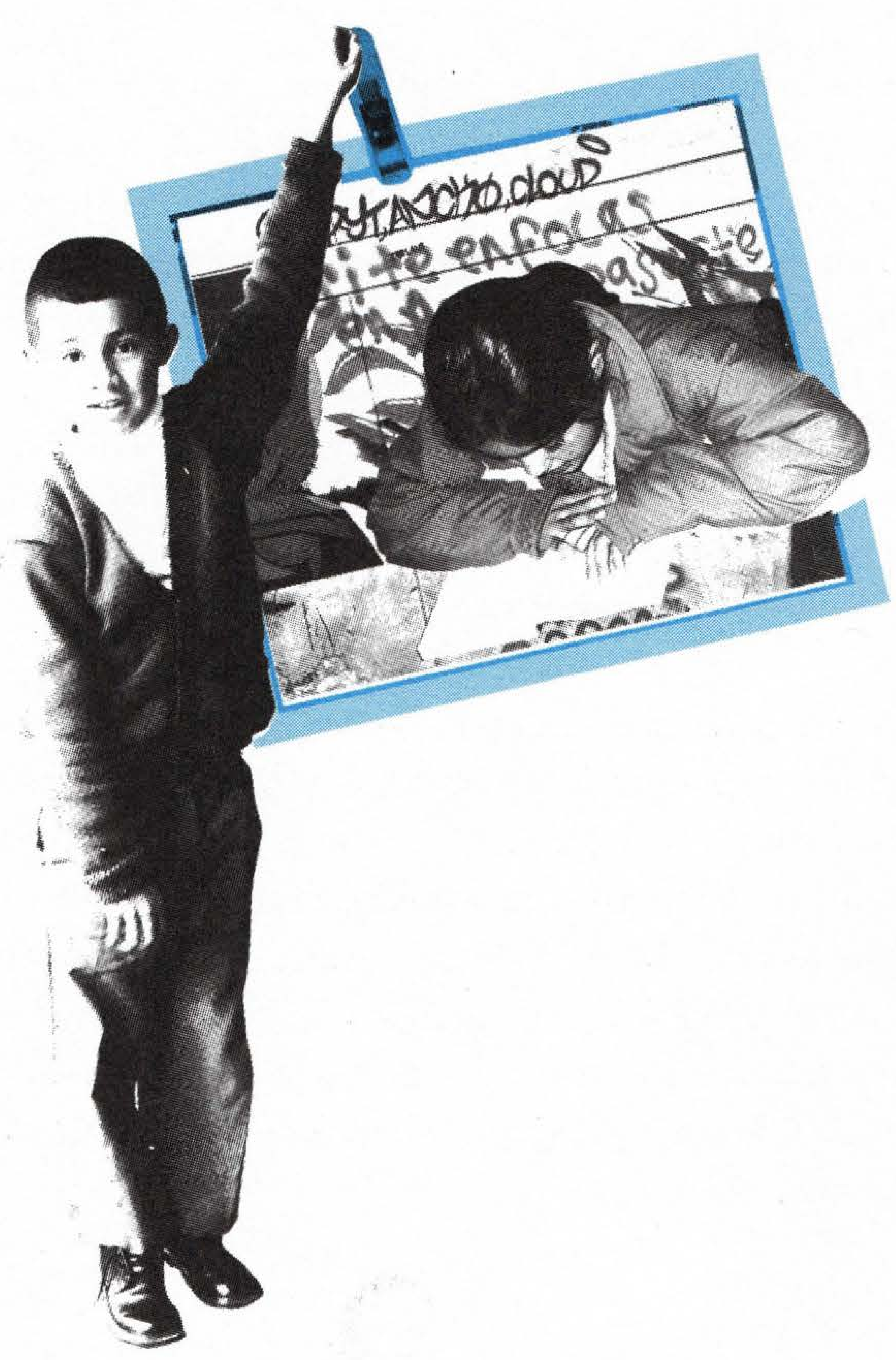

Un punto de partida para dar cuenta de este estado de las cosas acaso sea revisar a qué nos referimos cuando hablamos de lectura y qué representaciones sociales, qué ideas arraigadas sobre ella están en la base de los discursos sociales que se refieren a la lectura, entre ellos los pedagógicos y escolares pero también otros. Qué enunciados, qué figuras, qué metáforas nos hablan hoy sobre la lectura, enunciados, figuras y metáforas a partir de los cuales proponemos prácticas, promovemos, enseñamos, formamos, aprendemos, producimos un trabajo cultural, desarrollamos investigaciones, leemos y escribimos. Esta revisión es un punto de partida importante, como veremos más adelante, pues hace a una toma de posición pedagógica, determinante a la hora de facilitar o de obstaculizar prácticas de lectura y escritura en los más diversos contextos escolares y culturales.
Podríamos empezar dando cuenta del conjunto de sentidos usuales que se juegan en el discurso público; unos, referidos a la incidencia de la lectura en la formación del sujeto pues la lectura sería un ingrediente importante de esa formación en términos de "enseñanzas que la lectura deja", de "mensajes que nos transmiten los autores", de "moralejas a extraer"; una dimensión ética que se juega en la lectura que la escuela ha traducido como contenidos transversales. Otros, en relación con el beneficio informativo que supone la lectura y cierto valor instrumental y vinculado con la posesión de la información o la habilidad para desarrollar ciertas competencias discursivas, necesarias para la escolarización y junto con esta idea la de que la lectura es garantía para el libre ejercicio de la ciudadanía. 
Otros discursos más recientes afirman que la lectura contribuye en la construcción de la subjetividad y de la identidad de los lectores y por fin, acaso el más divulgado en el campo de la promoción, vincula a la lectura con la posibilidad del disfrute, del placer, del divertimento, y en su versión más compleja supone el acercamiento a cierta dimensión estética del lenguaje. Cualquiera de estos sentidos es retomado por metáforas en uso, pues a la hora de hablar de iniciación y formación la literatura es "un viaje", "un camino"; a la hora de disfrutar se habla del "placer de leer", a la hora de vincularse con la literatura de manera específica se dice que la lectura nos permite imaginarnos "otros mundos posibles". Estas y otras frases y metáforas recorren eslóganes y enunciados programáticos, estereotipos en boga en situaciones diversas y de variada índole. La pregunta que cabe es por el valor cultural y pedagógico de estos modos de decir la lectura, por el impacto que tienen en la construcción de una imagen social de la lectura y en el diseño de nuevas pedagogías, nuevos modos de aprendizaje y enseñanza.

La primera hipótesis posible es que quien adhiere a estos posibles valores de la lectura es porque ya ha dado algún paso previo en el proceso que permite la puesta en valor positiva de esta práctica cultural. Participar de la idea de que la lectura es un viaje porque nos permite el acceso a otros mundos, o que leer proporciona una cierta forma del placer, puede convertirse en enunciados sin sentido para quienes no participan de cierta esfera de uso del lenguaje o de cierta puesta en valor en el mercado lingüístico y de los bienes simbólicos. Ser parte de una cierta iniciación simbólica, partícipe de un cierto ritual cultural parece constituir un requisito necesario para que estos enunciados metafóricos no se conviertan en mueca insignificante y mera frase hecha de un sentido que queda disuelto en el acto mismo de su comunicación.

Otra línea a la hora de indagar los discursos sociales sobre la lectura, es analizada de manera esclarecedora, Anne Marie Chartier y Jean Hebrard ${ }^{1}$ quienes caracterizan los últimos veinte años en Francia atravesados por una producción de discursos sociales acerca de la lectura que con la adopción del concepto de "iletrismo" ponen en tela de juicio los resultados de la tarea del sistema de enseñanza, los métodos utilizados y por fin las actitudes de los propios sujetos. 
Discursos de tono apocalíptico, que se lamentan por la decadencia actual, que enaltecen una edad pasada, considerada como la edad de oro de la lectura, también estos discursos tienen sus modos de manifestarse en nuestros países. Precisamente en una investigación que he llevado adelante referida a los discurso acerca de la lectura en la Argentina en la última década observaba la fuerte presencia de estos discursos que hacen hincapié en el déficit, que describen las carencias de los sujetos y la ineficacia del sistema educativo, las falencias de los docentes y la pauperización de la cultura letrada. Discursos que están presentes en las intervenciones de escritores, de otros intelectuales, en las opiniones de periodistas culturales, de funcionarios políticos y de académicos.

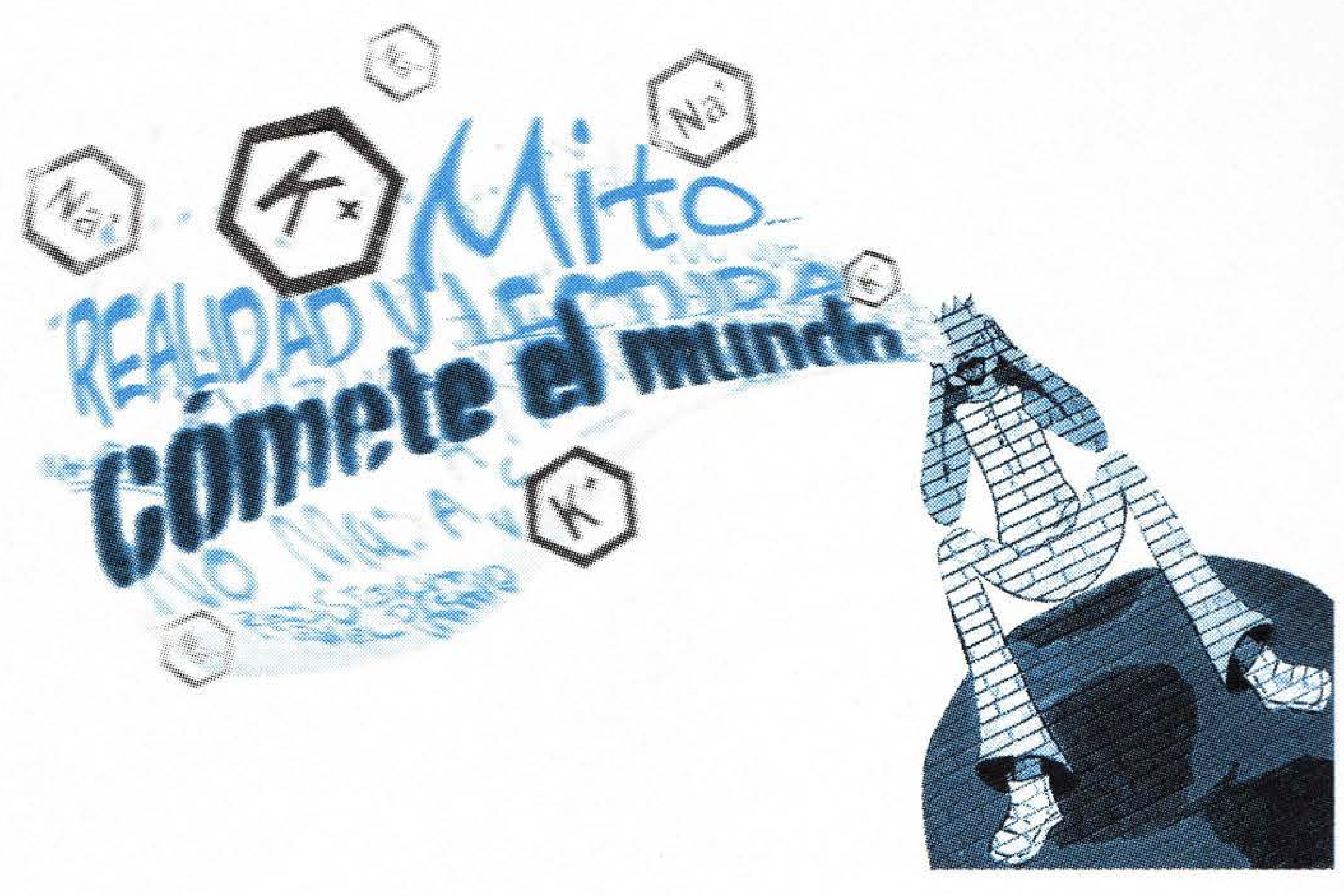

La tendencia a enarbolar estos discursos decadentistas suele apoyarse en datos empíricos aparentemente incontrastables que acuden a argumentos cuantitativos, pues sobre esas matrices están sostenidos. Los "cuantitofilicos", al decir de Ignacio Gómez Soto, en su trabajo Mito y realidad de la lectura², dan a estas cifras el valor de una evidencia indiscutible y su puesta en valor coincide con cierta tendencia del sentido común que es presa del dato numérico a la hora de comprender la gravedad de los hechos. Desde el campo pedagógico, inciden en la construcción de esta representación deficitaria de la práctica de la lectura, los resultados de los operativos de evaluación de la calidad educativa donde se ponen en juego estándares para la comprensión de los textos de niños y jóvenes de los distintos niveles del sistema. Estos diagnósticos, de utilidad para las gestiones de los sistemas educativos estatales, ofrecen en general y especialmente en nuestra región, resultados poco alentadores en los países de la región y en su difusión a través de los medios masivos de comunicación suelen generar de manera periódica un clima de estupor generalizado en la sociedad. 
Rápidamente relacionados con los resultados desalentadores, de las encuestas referidas al consumo de libros de texto por alumnos y otros indicadores (con comentarios como: "En la Argentina, se consume medio libro de texto por alumno y en Suecia siete"), el conjunto da la idea de una situación apocalíptica, de gravedad, sobre la que se trasmiten inmediatamente las más temerarias y diversas explicaciones. Darwinismo social, decadencia generalizada, triunfo en la batalla de los medios de comunicación y/o de las nuevas tecnologías versus el libro, apatía de los jóvenes posmodernos, efectos de la globalización, maestros poco idóneos para su tarea, ignorancia, brutalización, he oído al respecto las imprecaciones más duras de parte de periodistas, políticos, intelectuales, pedagogos, autoridades universitarias, editores, padres de familia, entre otros. El círculo parece cerrarse en una lógica sin salida, marcada por la culpabilización de sujetos e instituciones y por la insistencia que convierte al tema en noticia de tapa recurrente.

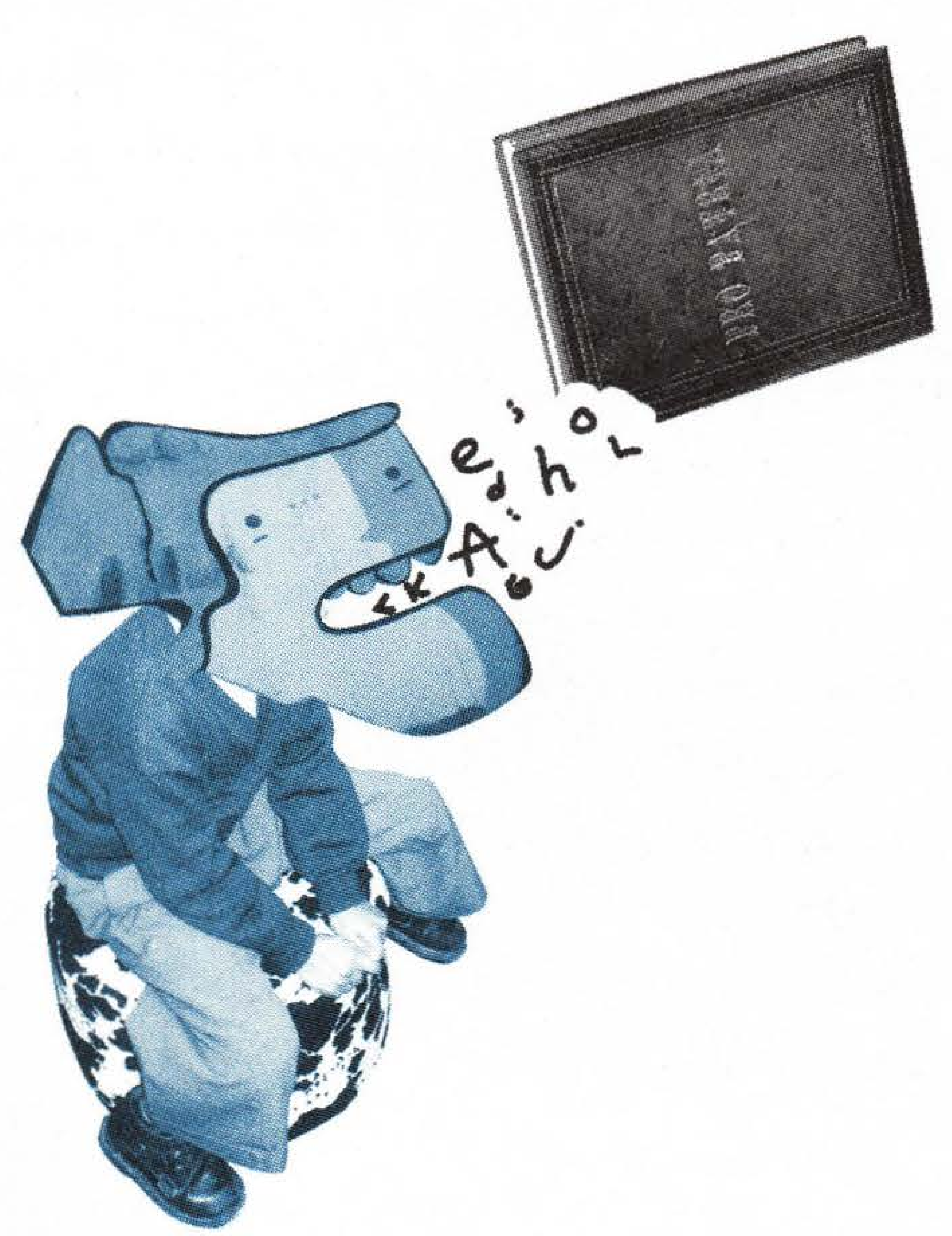

Esta discusión puede darse en dos planos, a los que mencionaré sin profundizar pero que creo que deben ser parte de una agenda de investigadores, pedagogos y gestores en este campo. Por un lado, una necesaria discusión acerca del alcance de los parámetros a partir de los cuales se determinan los estándares de comprensión y en qué sentido se tienen en cuenta variaciones sociolingüísticas y culturales que se ponen en juego en los modos de comprensión de sujetos que pertenecen a distintas comunidades. Estos modos de comprensión entendidos como parte de una experiencia cultural particular, rompen la ilusión de homogeneidad y cuestionan la posibilidad de pensar en estándares de comprensión. Más allá de las necesidades específicas de las gestiones de los sistemas escolares que apuntan a la construcción de un parámetro de homogeneidad, una mirada desde la promoción -y en este sentido uno podría decir que promover es también promover a los sujetos para que no sean excluidos del campo de la cultura escrita y del sistema educativo- deberá estar siempre alerta a la tensión que supone toda operación de homogeneización. Se trata de sostener una hipótesis rica donde la resistencia de sujetos y comunidades a la apropiación de estándares impuestos no debe leerse en clave deficitaria sino como parte de una dinámica cultural compleja de la que la escuela no puede ser ajena. 
Otra cuestión a considerar es, ¿Cuál es la conveniencia de la difusión de resultados de los operativos que se evalúan? Y podemos incluir entre estos a los más recientes de las pruebas PISA a nivel internacional. ¿Quién decide que esto ocurra? ¿A quién beneficia esta operación? ¿Qué efecto provoca en las representaciones sobre la lectura y sobre los lectores en situación de aprendizaje? De lo que se trata es de evaluar las consecuencias que esta difusión tiene en la construcción de representaciones acerca de la lectura, de su lugar en la sociedad y de los lectores y sus posibilidades al ponerse en relación con los textos. Estas construcciones que se presentan como negativas y alarmantes parecen tener un efecto pedagógico en la cotidianeidad del aula similar a esas representaciones sobre la inteligencia de sus alumnos que sostienen los maestros y que en las investigaciones realizadas por los sociólogos de la educación: "pueden marcar los límites que se le asignan a algunos alumnos de los cuales el maestro, sin ser conciente, puede esperar poco".
Hacerse estas preguntas y otras sobre las prácticas de promoción de la lectura y avanzar en investigaciones en este sentido, contribuiría a romper el círculo cerrado del discurso del fracaso, a cuestionar la profecía autocumplida de una sociedad a la que se señala en sus imposibilidades y déficit lingüísticos y culturales. Se trata de quebrar una lógica doblemente improductiva que va de la mmetáfora atractiva y biensonante pero excluyente al dato cuantitativo que alarma y paraliza. ¿Cómo salir de la lógica circular? ¿Cambiar los instrumentos de medición o cambiar las metáforas?

Uno de los caminos posibles o un atajo que al menos nos permite recuperar una imagen rica en términos de sujetos y de prácticas culturales y pedagógicas, de experiencias interesantes y de instituciones activas consiste en asumir una mirada social que permita reconocer escenas diversas en cuanto a sus participantes, su localización, su impacto, experiencias en las que lectura se presenta como un valor y sobre la que los sujetos ponen expectativas diversas.

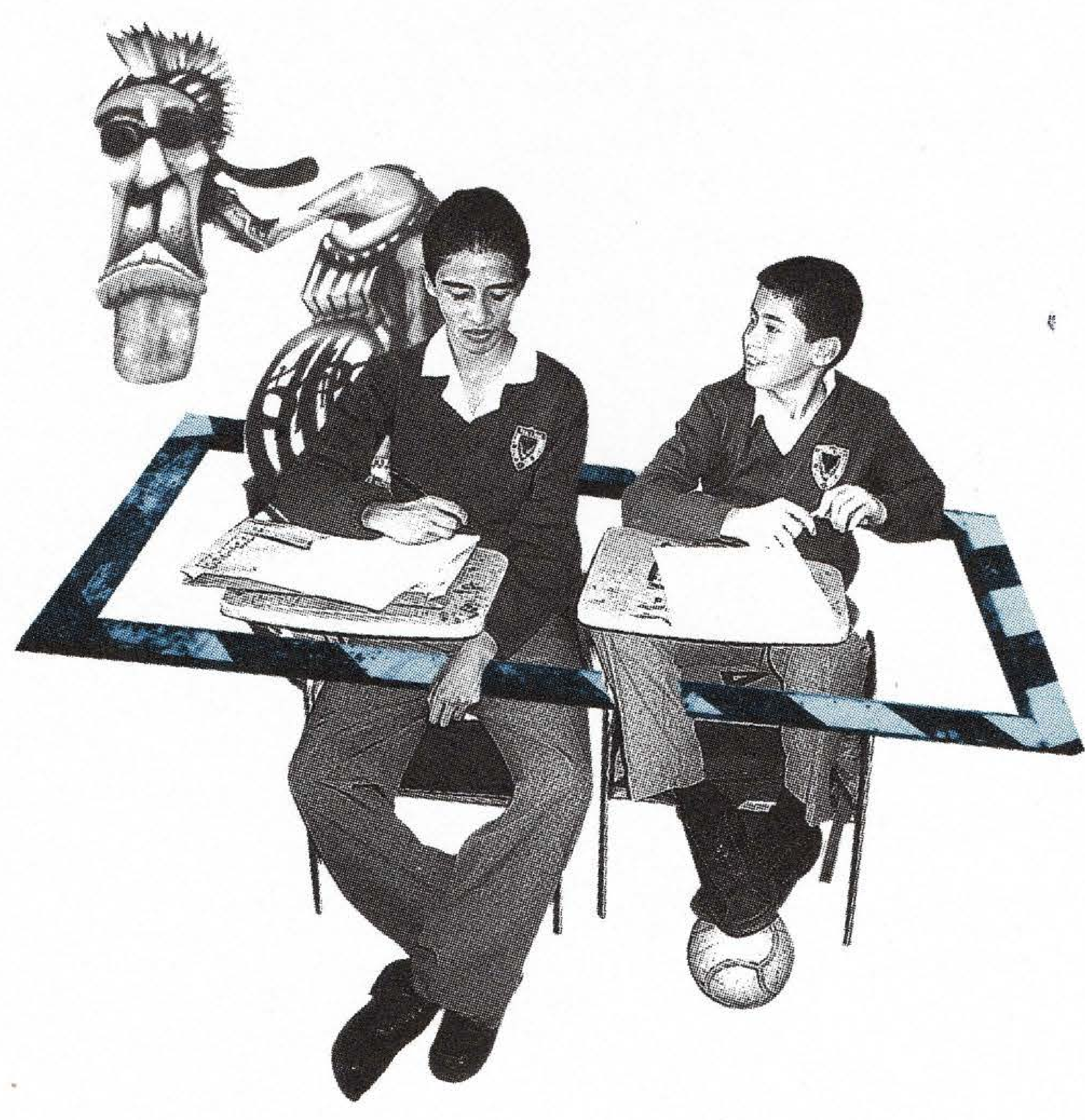




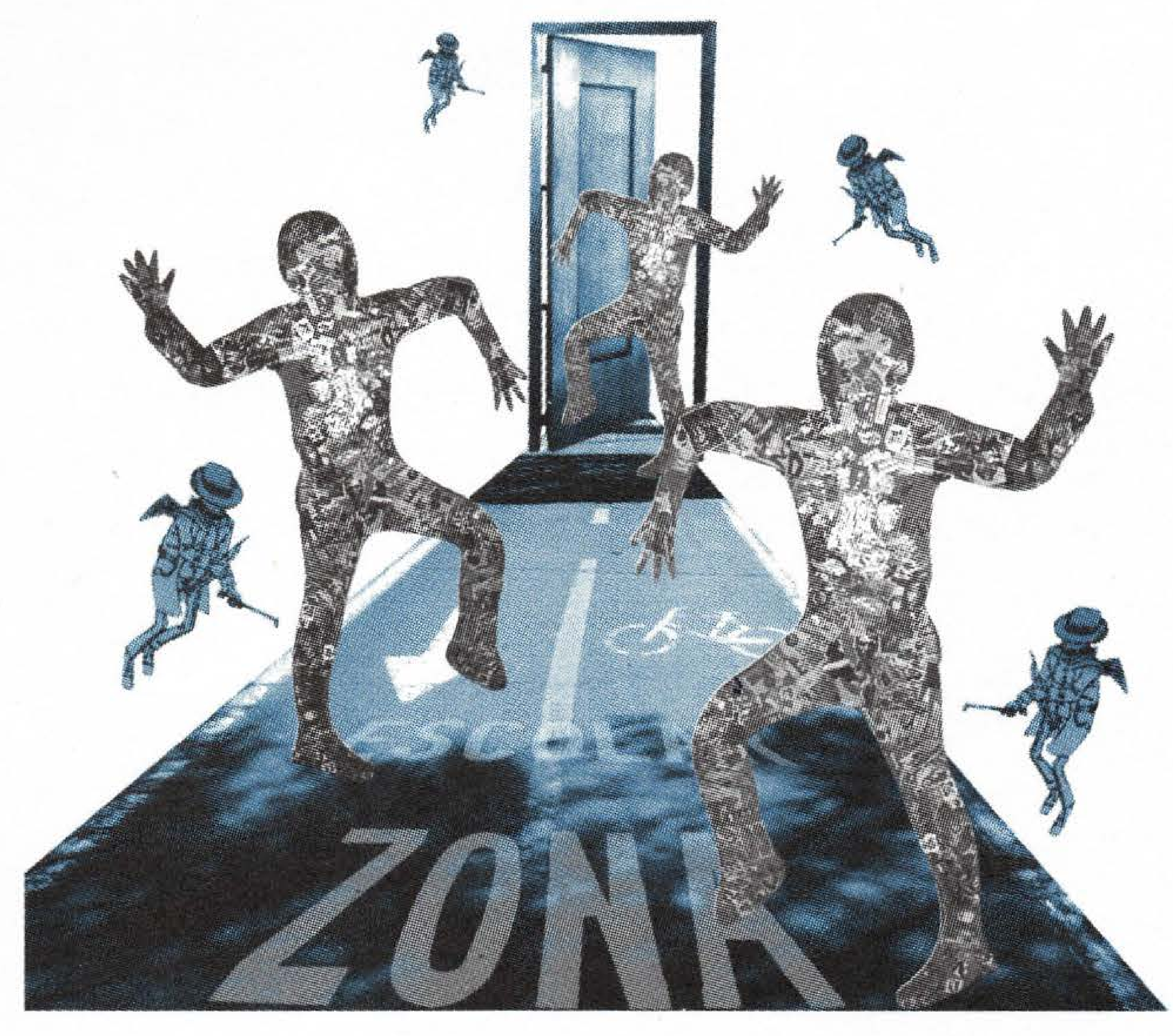

Si tuviéramos que describir y clasificar escenas y recorridos, tipos de experiencias y modos en que se producen, podríamos partir de la descripción de los contextos específicos en las que estas se producen; por ejemplo contextos de interculturalidad y bilingüismo, experiencias de educación penitenciaria, bibliotecas populares, espacios diversos generados por las organizaciones de la sociedad civil, contextos de escolarización de alta vulnerabilidad, entre otros.

La primera impresión que puede causar este catálogo de experiencias es la de una diversidad, diríamos, "políticamente correcta", a la cabe hoy prestar suma atención, en los países centrales y también en los de nuestra región. Seguramente lo es desde el punto de vista de la gestión educativa y cultural. Pero interesa aquí recuperarlas desde el punto de vista pedagógico y desde una reflexión sobre la lectura en tanto se trata de contextos que reclaman distintas "artes de hacer" como desafío.
En el reconocimiento de la diversidad de estas "artes de hacer" radica uno de los sentidos más importantes de lo que llamaríamos una perspectiva socio-cultural sobre la lectura. Se trata de recuperar lo empírico que en lo que tiene de particular, ofrece elementos a ser tenidos en cuenta para entender esos distintos modos en que los sujetos se vinculan con la cultura escrita. En este sentido cualquier operación de homogeneización impediría percibir esas particularidades y estaría, en algún sentido, violentando las lógicas de una comunidad a la que nosotros, como sujetos letrados y pertenecientes al campo de la cultura escrita, no conocemos en absoluto. Salvo que incurriéramos en una posición etnocentrista, el conocimiento de la lógica específica de los modos de vincularse con el conocimiento, con la lectura y con la escritura, los modos en que ciertos bienes culturales, en cierto sentido retaceados, se incorporan a la cotidianeidad de la vida de la gente es un campo sobre el que las teorías de la lectura y la escritura no han indagado suficientemente.

(a) 
En este sentido, otro recorrido posible, tal como lo plantea la investigadora mexicana Elsie Rockwell, es recuperar la dimensión biográfica del acceso a la lectura y la escritura. En esta línea ciertas investigaciones sobre la historia de la lectura nos dan pistas sólidas sobre el tipo de proceso cultural que se juega en las prácticas de lectura. Tal caso de Menocchio, un molinero friulano que murió en la hoguera en el siglo XVI, presentado en el magnífico ensayo de Carlo Ginzburg El queso y los gusanos que realiza su propia exégesis de la Biblia y argumenta en su propia defensa frente al Tribunal Inquisitorial. Menocchio, lector de la Biblia en lengua vulgar y del Decamerón de Bocaccio, entre otras lecturas, parece ser el modelo del lector moderno, dueño y señor de la interpretación, modo de leer que le vale la condena a muerte.

El conocimiento de estos casos de lectores particulares nos permite acumular conocimiento acerca de modos de leer de los sectores subalternos. En el mismo sentido, las historias de las prácticas escolares de lectura y escritura que muestren las dimensiones complejas de cómo se producen estas prácticas, las alternativas que se juegan en los debates curriculares, las querellas metodológicas, los procesos de inclusión y exclusión de textos, etc. ofrecen casos interesantes de ser estudiados como los relatos de los maestros que han desarrollado prácticas innovadoras. Rockwell da cuenta por su parte de relatos sobre caminos alternativos para al acceso a la escritura por parte de miembros de comunidades indígenas. Podríamos citar el caso de los trabajadores del tabaco en Cuba que acompañan su tarea cotidiana con lectura en voz alta o el de las llamadas "lecturas comentadas" dispositivo desarrollado por los grupos anarquistas, que entre muchísimos otros parecen, por una parte, relativizar el monopolio universal de la escuela a la vez que muestran contextos y modos de apropiación posible de la cultura escrita en la que se desarrollan las diversas tácticas que los sujetos ponen en juego y que los muestran activos y que parecen devolvernos una imagen no deficitaria al menos en su posición frente a las prácticas de lectura y escritura.

Los movimientos sociales actuales (grupos indígenas de Chiapas, el movimiento de los "Sin tierra" en Brasil, algunos grupos piqueteros en la Argentina) -y habría que seguir indagando- desarrollan experiencias de apropiación de la lectura y la escritura. En este sentido nos bastan las pequeñas muestras que nos ofrece Michele Petit ${ }^{3}$ en sus investigaciones sobre cómo los jóvenes provenientes de familias migrantes se acercan a la lectura y transforman sus vidas en ámbito propicio de la bibliotecas públicas de Francia.

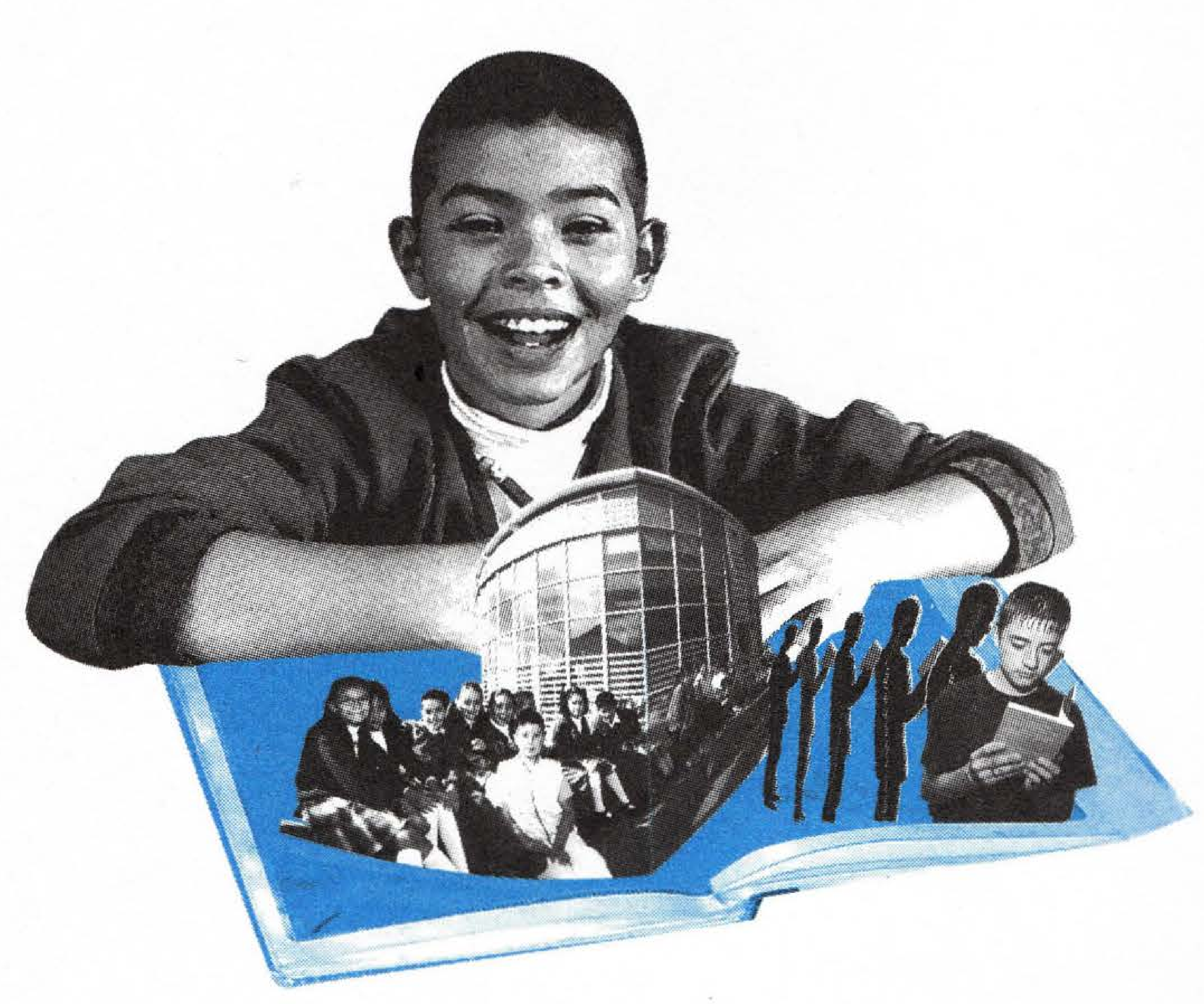

3 Petit, Michele. Lecturas: del espacio íntimo al espacio privado. México: Fondo de Cultura Económica, 2001. 
Se trata de espacios y comunidades en las que se dibujan distintas valoraciones de lo escrito, relaciones diferentes entre los sujetos, las familias y las prácticas de lectura y escritura, diferentes a aquellas que nosotros como sujetos alfabetizados pertenecientes al ámbito del sistema de la educación formal y con los beneficios de integrar las clases medias tenemos como imagen deseada de la construcción de la relación con la cultura escrita. Se suele oír en las conversaciones cotidianas en las escuelas argentinas que es bueno que las familias colaboren con la escuela en la tarea de alfabetización o de formar lectores y también se suele decir que las dificultades de los chicos para convertirse en lectores tienen que ver con que ya no cuentan con el apoyo de sus familias, lo que explicaría -según estas posiciones- el fracaso escolar, insistiendo de esta manera en sostener una representación de familia dotada de bienes simbólicos y materiales, homogénea y estable, solo y hasta cierto punto para una clase social determinada.

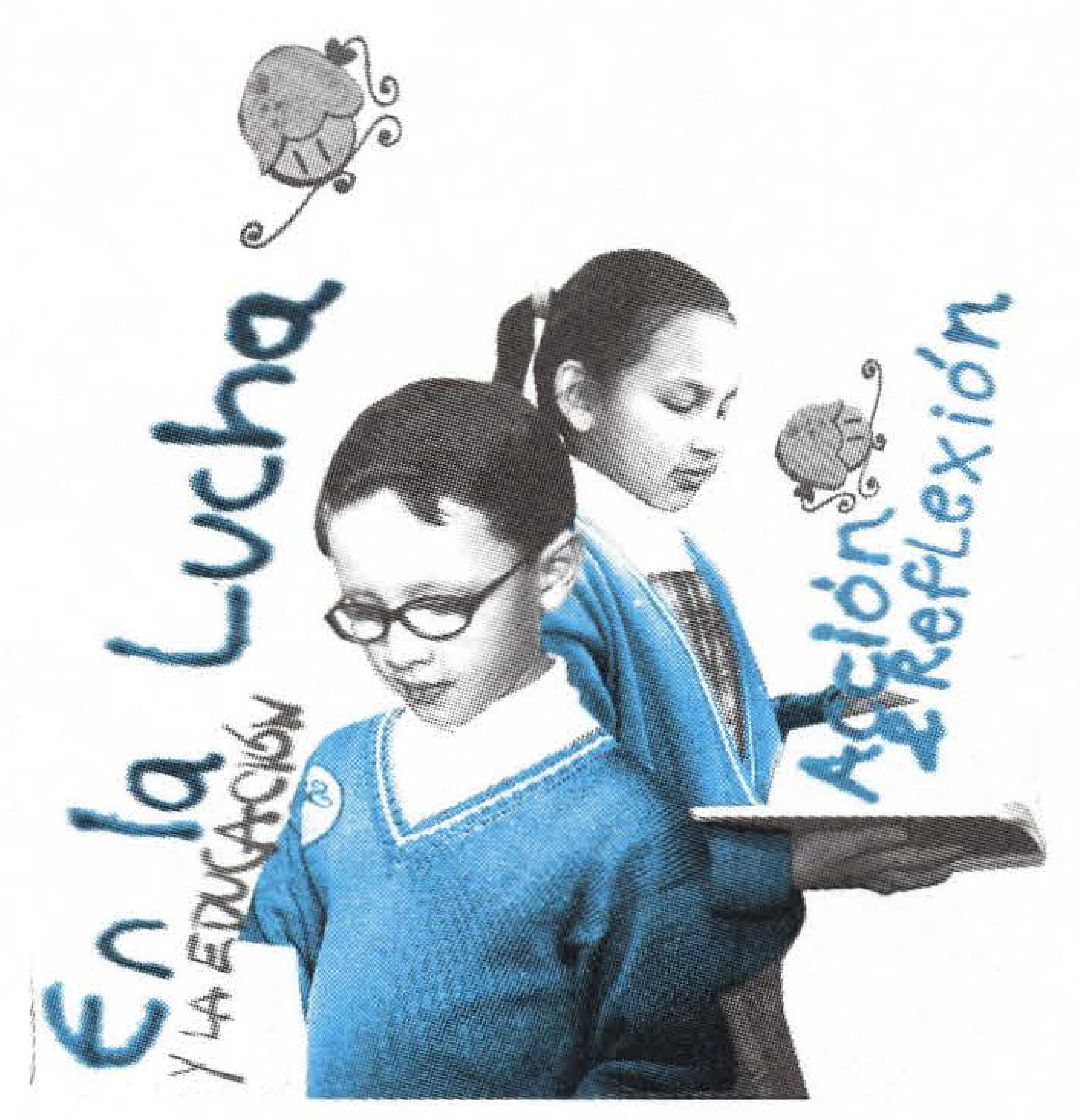

Investigaciones llevadas a cabo por un grupo de didáctica de la literatura y literatura infantil de la Universidad Nacional del Comahue, en la carrera de Ciencias de la Educación, examinan las prácticas de lectura de niños provenientes de sectores desfavorecidos en la zona de la precordillera, uno de los aspectos más interesantes está referido a la observación de ciertas maneras de leer que llevaban adelante niños de séptimo grado en la que se advertía por un lado, la incidencia de otras experiencias culturales, ligadas a la exposición a la televisión y por otro, ciertas construcciones de sentido realizadas dentro del aula que en muchos casos, si bien operaban como efectivas lecturas del texto, lo hacían construyendo sentidos a contrapelo de los sentidos "oficiales" que desde el frente del aula propiciaba un maestro quien a su vez formaba parte del equipo de investigación. A ese modo de posicionarse en la lectura lo llamamos "poética de los chicos" como un modo de leer diferenciado de aquél que el maestro y los propios investigadores esperaban acaso más ligado a esa escena de lectura de la tradición escolar. En un atractivo artículo Margaret Meek nos recuerda la necesidad de prestar atención a los modos en los que los niños leen, no los mejores sino todos, aún los que son lectores potenciales, lo que llevaría, dice, a crear "una poética de la literatura para niños y de lectura de los niños"». Practice, vol. XXI, N4, 1982. Traducido en: Un encuentro con la crítica y los libros para niños. Caracas: Parapara Clave. Banco del Libro, 2001. 
Algunas experiencias realizadas en distintas regiones del país desde el ámbito del Ministerio de Educación de la Nación Argentina, nos alertan sobre nuevas maneras de circulación de la cultura letrada. Recuperando algunas líneas de trabajo en lo que se llama "promoción de la lectura" (entre ellas el grupo francés "Peuple et culture" retomadas en las experiencias realizadas en los años '60 por la Dirección de Extensión Universitaria de la UBA en Isla Maciel -un poblado en el límite entre la Ciudad de Buenos Aires y el conurbano), se organizaron talleres para la formación de narradores orales entre miembros de la comunidad de adultos mayores de un comedor infantil en un barrio pobre de la Ciudad de Paraná. La idea es que estos adultos mayores se formaran en el conocimiento de cuentos de literatura infantil y que pudieran leer en voz alta de manera atractiva esos cuentos a los más de 150 chicos que diariamente asisten a este comedor a almorzar. Lo que no se había previsto es que entre ellos hubiera adultos analfabetos que para suplir esa competencia se hacían leer los cuentos por otros adultos para aprenderlos de memoria y así poder narrarlos a los chicos. De esta manera estos adultos analfabetos desarrollaron una competencia por cierto más compleja que la lectura en voz alta, que es poder re-narrar un cuento sin leerlo, elaborando sus propias versiones.

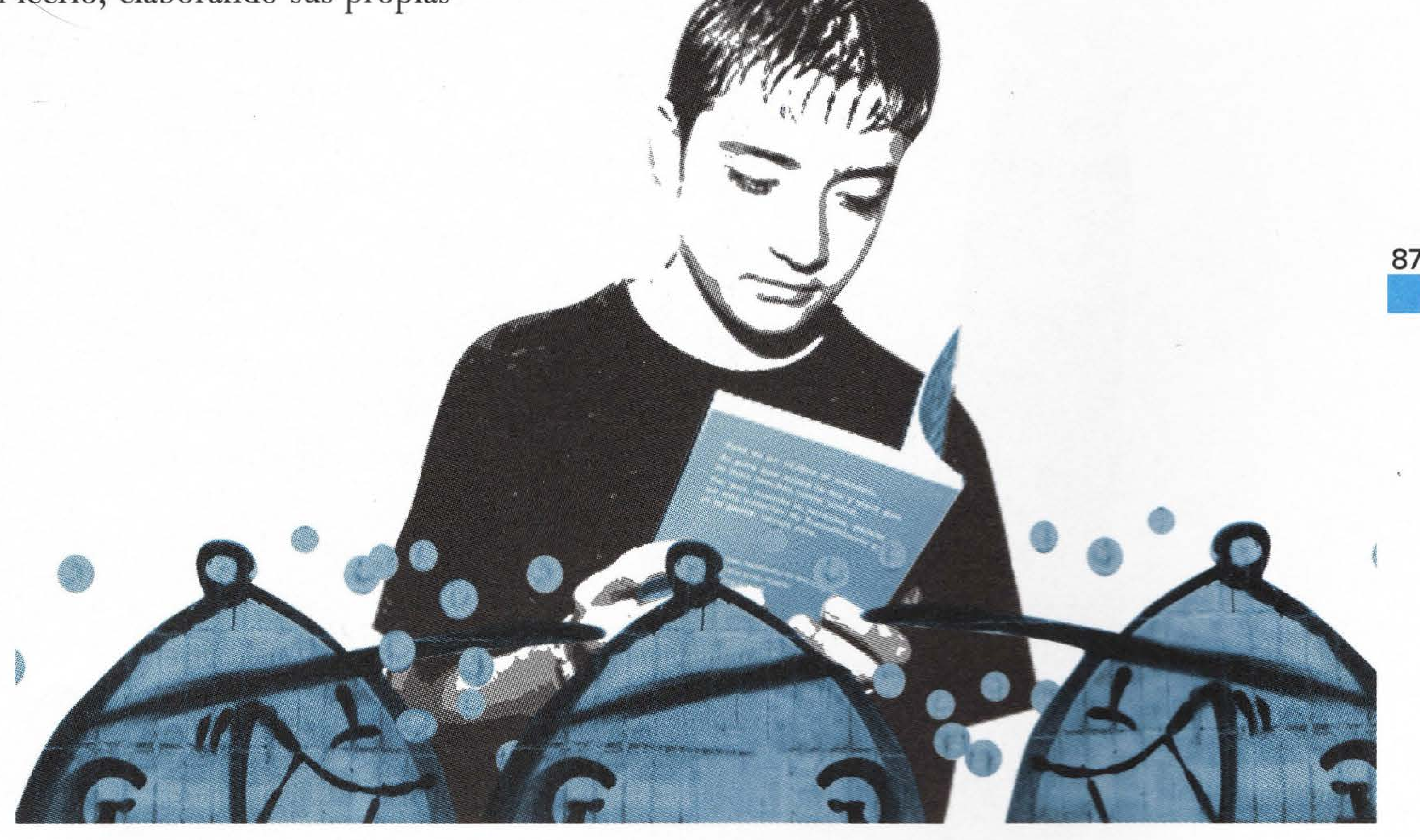




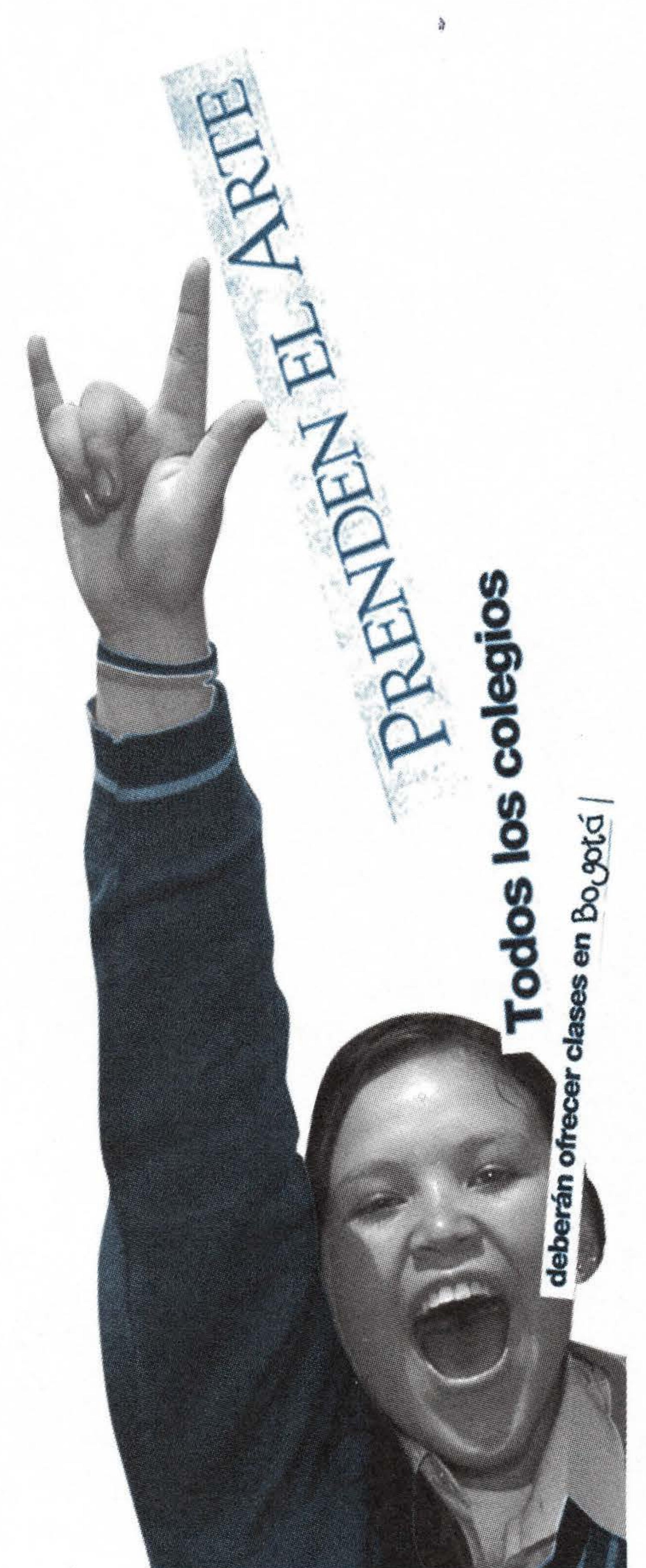

Otro ámbito posible es el de la educación penitenciaria: cárceles de adultos e institutos de minoridad. Se trata de espacios donde la puesta en acción de proyectos de lectura reconoce una complejidad particular. En cierta experiencia realizada en Instituto Gregorio Araoz Alfaro de la ciudad de La Plata, la profesora Liliana Peralta recurrió a una estrategia clásica de trabajo en taller de lectura. Partió de la idea comúnmente aceptada en el campo pedagógico de que primero se lee y luego se escribe, la lectura es pretexto y condición para el desarrollo de la práctica de escritura. Luego de varias sesiones en las que una única actitud de parte de los alumnos era la de la resistencia, el desorden y la falta de tarea, sucede -de manera casual- que a la profesora se le cae una fotocopia de un poema de Mario Benedetti que tenía preparado para otro grupo de la misma institución que sí estaba trabajando con la propuesta inicial. Uno de los chicos del grupo, el "líder" recoge la fotocopia y comienza a leerla en voz alta. Mientras lee va tomando algunas decisiones que consisten en marcar el texto, en suprimirle palabras, en reemplazar unas palabras por otras que fueran más entendibles; la tarea es compartida por el resto de los compañeros y se produce un ejercicio activo con la lengua, un ejercicio de escritura de la lectura que los saca de ese lugar de apatía y falta de tarea que se venía presentando en las reuniones anteriores. La escritura es ahora verdadero palimpsesto al servicio de los procesos de significación. El mismo grupo posteriormente avanzó en la tarea de producir una revista y muchos de los textos -tal como fueron leídos en una jornada de trabajo por los propios adolescentes reclusos en una visita que hicieron a los alumnos de la Cátedra de Didáctica Especial y Prácticas de la Enseñanza de la Universidad Nacional de La Platatrabajaban esta estrategia de apropiación, de "hurto" de palabras para la confección de nuevos textos: así fragmentos de textos sin entrecomillar de Mario Benedetti, Pablo Neruda y otros autores se integraban en un mosaico textual de gran creatividad y complejidad en su composición. 
Otro ejemplo posible, es el de una experiencia recientemente realizada como trabajo final de aprobación del Postítulo de Literatura Infantil y Juvenil, en la Estación Flores de la Ciudad de Buenos Aires. Se trata de la cartoteka, una caja con libros que un equipo de profesoras de distintos niveles acercaba cada lunes por la tarde en el año 2003 al grupo de niños y adultos que acomodaban cartones recogidos por las calles de Buenos Aires, antes de de tomar el llamado "tren blanco", un tren especialmente acondicionado para que los "cartoneros" puedan hacer su viaje con el material de desecho recogido que luego será vendido en el conurbano bonaerense. Los padres acomodan cartones, desechan otros, los disponen para mejor transportarlos en el tren, mientras que los niños colaboran en la tarea. La cartoteka irrumpe y altera las rutinas. Padres y madres incitan a sus hijos a abandonar las tareas y a ponerse en contacto con estos otros cartones y papeles que son los libros, de todo tipo y géneros, infantiles, libros álbumes. Los niños se entusiasman con las tareas y poco a poco los adultos se acercan a las profesoras y recuerdan otros momentos de la vida, cuando tenían empleo y también leían y tenían libros y tiempo para la lectura, lecturas informativas, de historia, literatura, García Lorca entre otros. La lectura irrumpe en la escena de la tarea del desempleado que ahora vive de juntar cartones y demuestra su poder convocante, su puesta en valor.
La lectura está presente como práctica efectiva en la vida de sujetos y comunidades y las categorías posibles para la evaluación y análisis de estas experiencias, ya no serán las de la investigación cuantitativa. Se trata de recurrir a parámetros de la investigación cualitativa, que rescaten de esas escenas aquellos elementos que las definen en su propia lógica, suspendiendo la evaluación y propiciando la comprensión y la interpretación de esas experiencias. Los datos recogidos ya no asumen la forma de la estadística sino la de la narrativa, nos hablan acerca de otros modos en que la lectura puede ser valorada en nuestras sociedades. Ya sea en el ámbito escolar o fuera de él, y en la riqueza que supone la atención simultánea, una perspectiva social nos obliga a construir una mirada diferente sobre las prácticas de lectura.

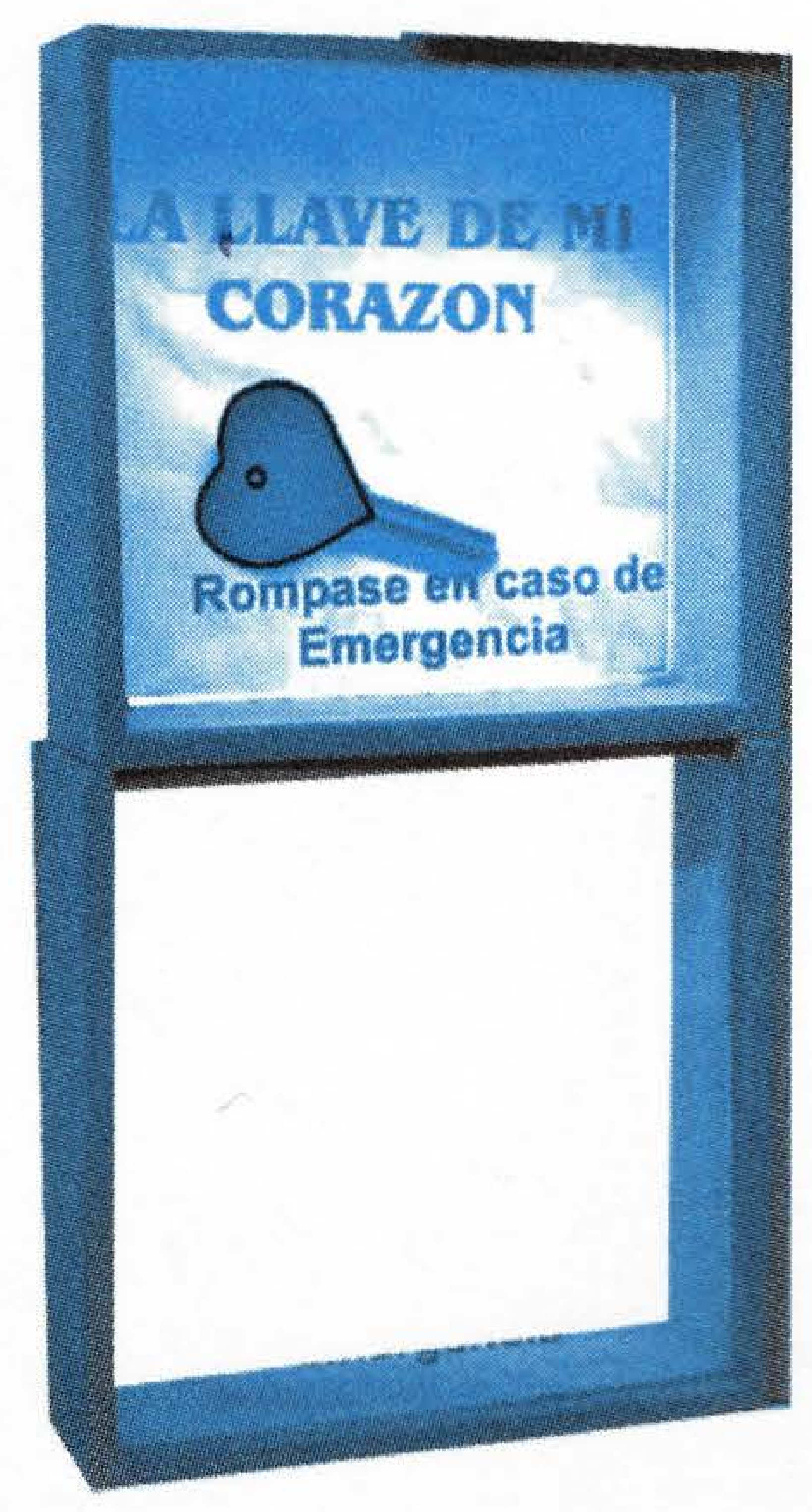


Frente a experiencias disímiles, en el ámbito escolar y extraescolar, vale preguntarse: ¿a qué teorías recurrir?, ¿cómo seleccionarlas?, ¿cómo recortarlas?, ¿para qué usarlas?, tanto en la planificación como en el análisis de estas prácticas.

Los supuestos de una teoría de la lectura o al menos de un modo de leer fuertemente institucionalizado producto de la tradición escolar moderna, como escena de lectura fundante de la escuela moderna -al que en otro lugar he llamado "aparato interpretativo escolar"-, opera como un telón de fondo que es necesario poner en discusión a la hora de enfrentarnos con situaciones empíricas complejas en términos de diversidad socioculturales y situaciones de pobreza y exclusión. Seguir insistiendo sobre esa escena escolar fundante, tomarla como parámetro de logro para la tarea pedagógica, defenderla como única posibilidad para lo observable hubiera sido reproducir la operación violenta en lo simbólico que realiza la escuela homogeneizadora con los sectores excluidos contribuyendo a la construcción de experiencias de fracaso escolar y de exclusión de la cultura letrada. Precisamente porque los diagnósticos nos dicen que la escuela en la Argentina construye cada

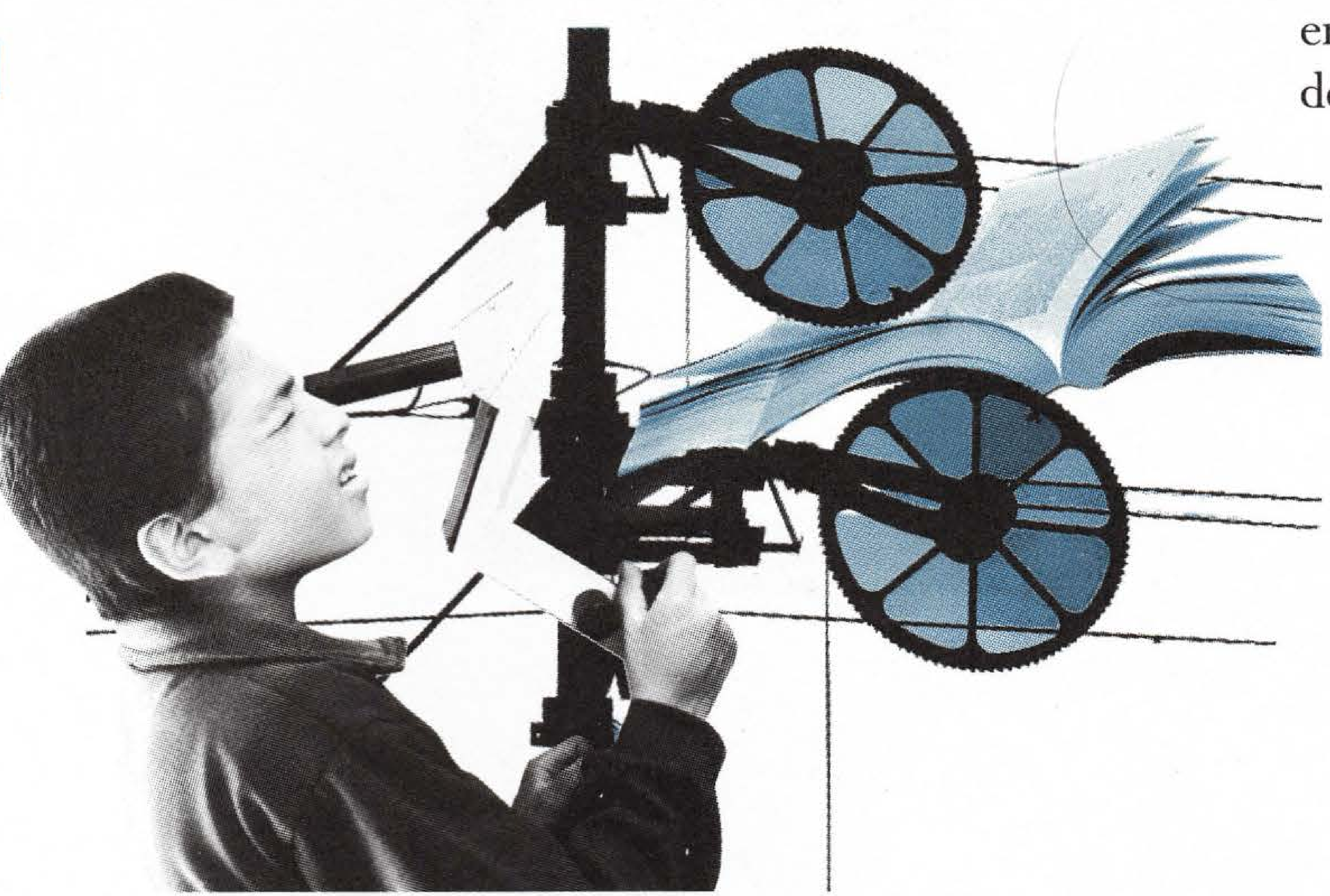

vez más fracaso en términos de cifras de deserción y de desescolarización es que nos proponemos pensar las relaciones de enseñanza de la lengua y la literatura y de promoción de la lectura de una manera nueva con el objetivo de construir lo que podríamos llamar una teoría empírica de la lectura en contextos pedagógicos.

Lo interesante de estas experiencias e investigaciones en términos teóricos y metodológicos es que aportan elementos para la construcción de una teoría empírica de la lectura puesta en juego en situaciones pedagógicas en las que es posible percibir la productividad de las lecturas que los lectores realizan cuando se distancian de aquellas más subsumidas en los paradigmas escolares de lectura y en las que se juegan además características idiosincrática de los sujetos que inciden en la construcción de sus modos particulares de leer.

Pero ¿cómo traducir en términos de acción pedagógica, de gestión educativa, de formación docente, de una posición que llamaría "comprensiva" respecto de las posibilidades de trabajar en prácticas de lectura y escritura con vastos sectores del sistema de la enseñanza pública y de la sociedad en general? ¿Qué estrategias de formación y capacitación, qué modos de intervenir en las prácticas culturales que efectivamente se producen en la escuela y en la comunidad en general, contribuirían a construir una representación positiva en relación con las posibilidades de los sujetos que participan en las distintas escenas de lectura? ¿Cómo traducir esta direccionalidad en acciones específicas que sean directrices de un Plan de alcance nacional? 


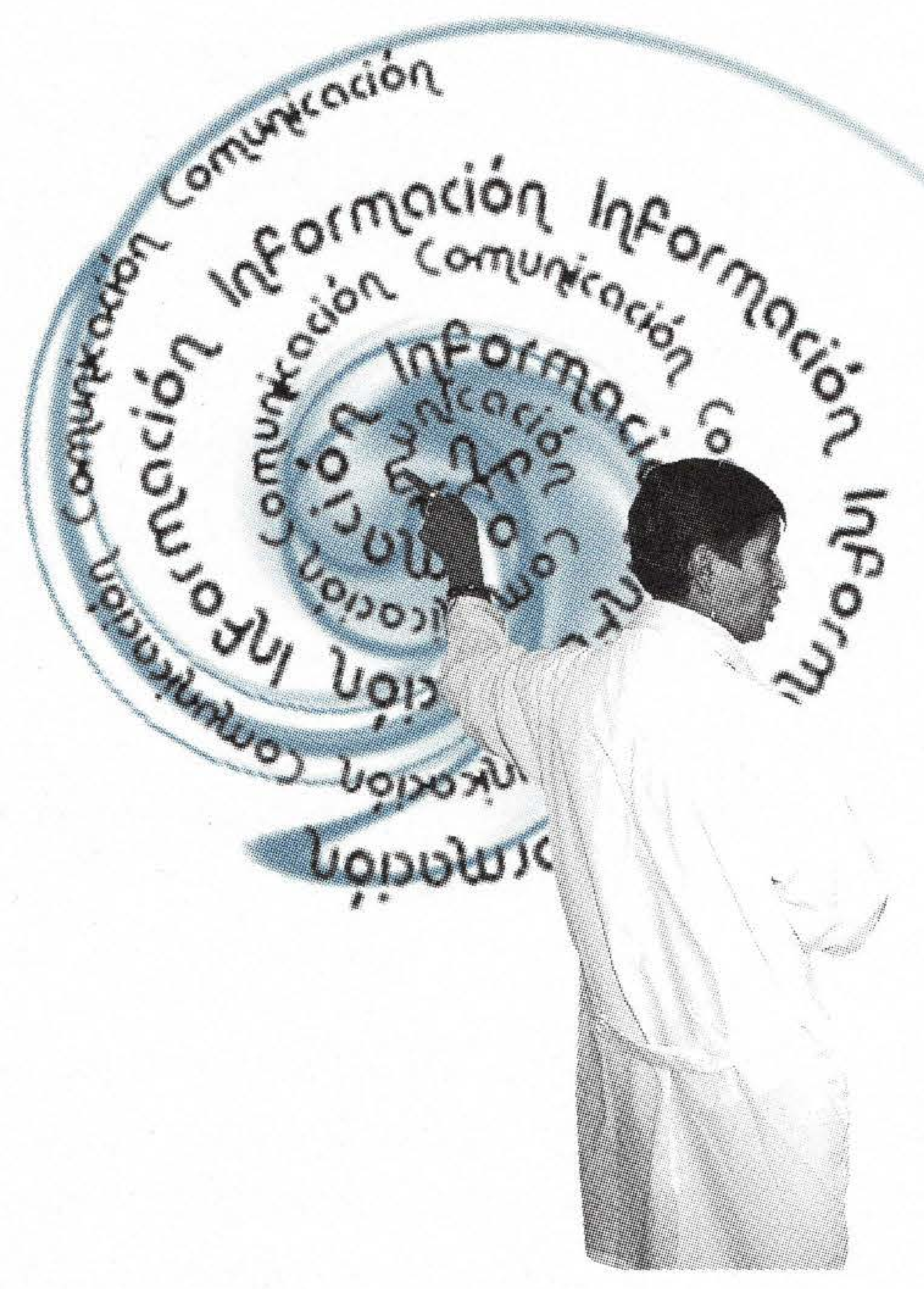

Cabe primero hacer una caracterización del sistema educativo argentino que permita dar cuenta de la complejidad que supone avanzar en líneas de trabajo que permitan articular políticas de lectura de alcance nacional. Por una parte, en la última década se terminó de consolidar el proceso de transferencia de los servicios educativos de la Nación a las provincias. Esto quiere decir que ninguna escuela del país depende de manera directa del Ministerio Nacional Argentino. Son los veintitrés estados provinciales y la Ciudad Autónoma de Buenos Aires los que administran y gestionan pedagógicamente las escuelas. Sin embargo y para evitar caer en el riesgo de una total atomización del sistema educativo nacional, el Ministerio de Educación de la Nación cumple una función rectora en el desarrollo de lineamientos en relación con la formación y la capacitación docente, de asistencia técnica en relación con estos lineamientos, y de evaluación y de asistencia compensatoria en relación con las zonas más críticas del sistema educativa (desarrollo de infraestructura, dotación de libros, entre otras tareas).
Una de las líneas de trabajo en relación con lo pedagógico se desarrolla desde la Dirección Nacional de Formación y Capacitación Docente que provee de lineamientos específicos y de recursos presupuestarios para el desarrollo de líneas de capacitación de docentes en servicio. A través de la Red Federal de Formación Docente Continua, las provincias presupuestan sus proyectos de capacitación. Dentro de esta Dirección Nacional se halla la coordinación del Plan Nacional de Lectura que articula el desarrollo de la política pública de lectura dirigida a las escuelas de todo el país. Veinticuatro jurisdicciones divididas en cinco regiones que van de la remota y despoblada Patagonia a la central Ciudad de Buenos Aires, pródiga en ofertas culturales, el densamente poblado y violento conurbano bonaerense, las tradicionales Córdoba y Santa Fe, las empobrecidas regiones del noreste y noroeste, con características culturales diferenciadas, ligadas a las culturas guaraníticas y andina., constituyen un desafío de gestión pedagógica y cultural si enfrentamos el reto de entender la diversidad como punto de partida ineludible. Se trata de aceptar la diversidad cultural como problema y en tensión con la lógica homogeneizante de la cultura escolar como escenario de las prácticas de promoción, como condición para avanzar en una construcción que no opere ejerciendo violencia o imposición desde el centro y que a la vez facilite una equilibrada circulación de los bienes culturales. 
Difícil contrabalancear en un escenario caracterizado por desproporciones y diferencias. La primera acción es recuperar aquellos proyectos, experiencias y acciones realizadas en cada región de modo de reconstruir un mapa de la lectura, no ya el de los déficit sino aquel que muestre la riqueza de experiencias y el poder convocante del tema de la lectura. Un tema que no requiere de ninguna etapa de sensibilización sino el apoyo necesario. De este modo un referente designado por cada ministerio provincial se convierte en el interlocutor privilegiado hacia la propia comunidad y hacia el Ministerio Nacional. A su vez, este referente -convertido ya en un virtual coordinador de plan de lectura provincial arma un equipo técnico de número variable y que se iría incrementando año a año, de especialistas en lectura, literatura, literatura infantil, bibliotecas, narración oral, preparados para desarrollar tareas de capacitación docente y a la vez con un perfil de promotor cultural.

La diversidad hace a los modos de gestionar y de hecho un panorama inicial -sobre el que habrá que seguir profundizando- nos muestra lo desparejo, lo desacompasado de los avances según las jurisdicciones y en relación con infinitas variables. No se trata de evaluar retrospectivamente, sino de tender a articular estrategias claras y sostenidas que permitan fortalecer lo ya hecho y lo por hacer en cada una de las jurisdicciones. En términos generales podemos decir que las jurisdicciones han encarado sus acciones y políticas de lectura en tres direcciones:

a) Por un lado aquellas provincias que le han dado un carácter sistemático a las tareas de promoción de la lectura desarrollando programas y planes de lectura y tratando de establecer responsables técnicos de gestión de carácter estable.

b) Por otro lado aquellas provincias que buscan amalgamar líneas de acción y experiencias aisladas tendiendo a la priorización del tema de la lectura y a la construcción de programas más estables.

c) En tercer lugar aquellas jurisdicciones que han ligado la lectura a lo curricular y lo específicamente pedagógico ya sea como una preocupación propia del campo de la enseñanza de la lengua o al campo de la alfabetización inicial o de manera transversal entendiendo a la lectura como una habilidad necesaria para que se produzcan los aprendizajes en todas las áreas de conocimiento.

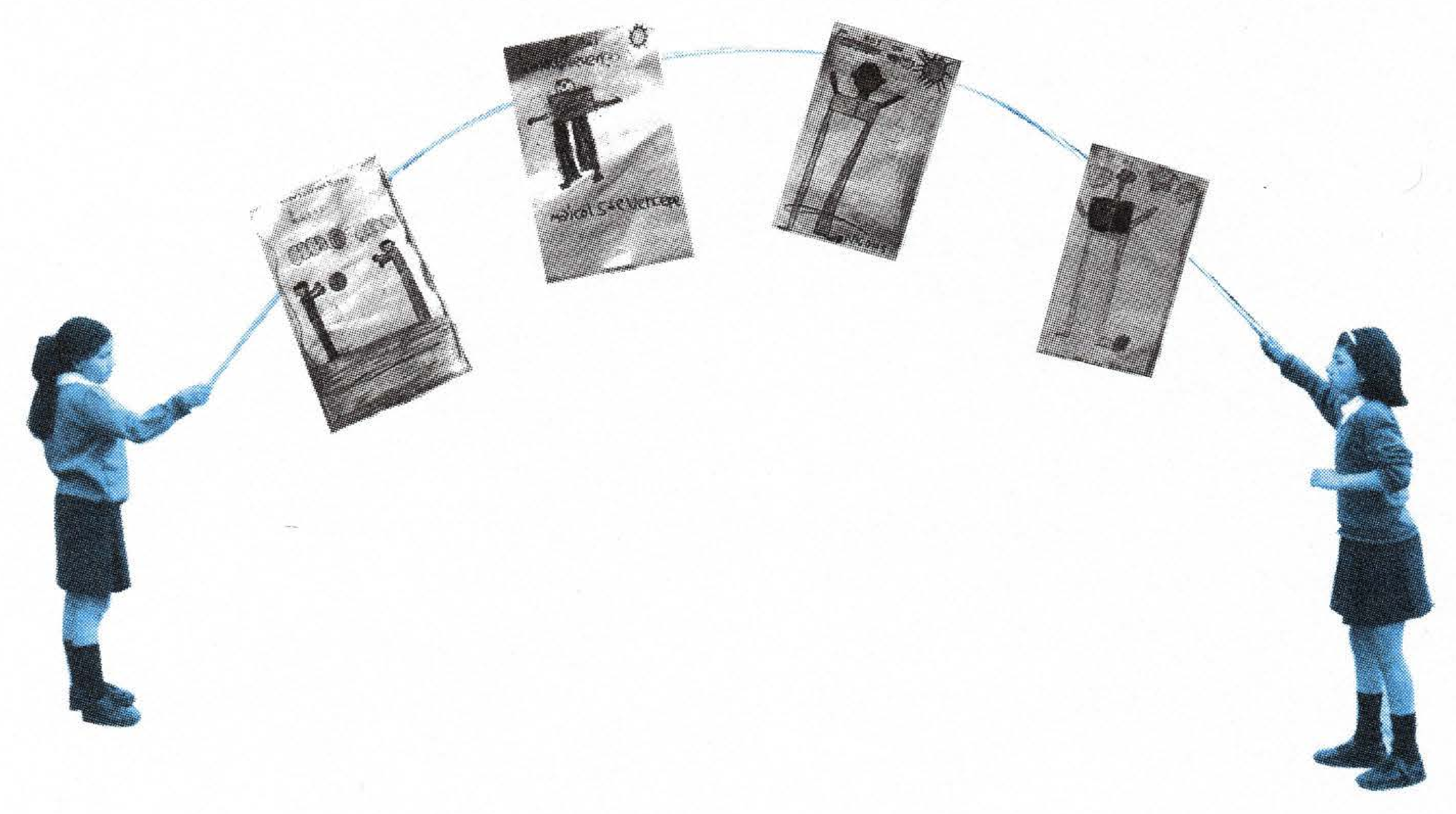


Visto este panorama, tratamos de buscar nuevas definiciones que dieran cuenta de lo específico del contenido de un plan de lectura de un ministerio de educación que depende del área de gestión curricular pero no del área curricular de lengua y literatura, que coloca a lectura en el centro de sus preocupaciones pero que trata de extender la mirada más allá de la dimensión estrictamente curricular. Para esta decisión nos valimos de algunos de las posiciones sobre la lectura ya mencionadas que reconocen el carácter socio-cultural de esta práctica y partimos de la convicción de que la tarea de promoción de la lectura no se agota en la gestión curricular dentro del aula sino de que se debe reconocer una mirada ampliada sobre las prácticas de lectura. Estas líneas no son meramente prácticas o sólo referidas a la gestión sino que se proponen como contenidos pedagógicos propios de un proyecto de lectura que busca superar la concepción de la promoción como mero dispositivo que muestra, recomienda, resalta, invita al placer o describe las bondades de la lectura. Se trata de superar cierto vacío de sentido que se observa en los proyectos de lectura que se mecanizan, que se enuncian de maneras estereotipadas y que reducen la práctica de lectura a un ritual convencionalizado y de escaso impacto.
Una larga tradición de enunciados propositivos que naturalizan la relación de los sujetos con la lectura, entendida casi como una escena idílica que se da de suyo, que se conforma con la promoción de un día de fiesta en que los niños leen, para la que poco importan las enseñanzas efectivas y la intervención del maestro, necesita de la construcción de un entramado complejo que vincule las posibles prácticas escolares con las prácticas sociales de lectura y que a su vez no desatienda al aula y a la dimensión curricular como tiempos y espacios donde muchos niños, acaso los que tienen más negadas las experiencias culturales pueden hacer posible su ingreso al mundo de la cultura escrita.

Una primera línea de trabajo comienza por interrogar a los propios adultos, los docentes, como lectores. Se parte de la convicción de que un mediador de lectura es solo aquel que reconoce en su propia trayectoria profesional y como sujeto autónomo perteneciente a una cultura una relación posible con la lectura. Invitar a los docentes a leer, hacerlo desde una instancia de capacitación, proponiéndole que se olvide, que ponga en suspenso por ahora sus preocupaciones de enseñanza, de contenidos curriculares, de métodos, propone un desafío para la identidad profesional del docente y lo invita a colocarse en el lugar de un agente cultural. Las primeras observaciones en este campo -realizadas por la colega Alcira $\mathrm{Bas}^{5}$, a cargo de esta línea- nos permiten detectar distintos perfiles: docentes que se consideran lectores y que se incluyen en esa categoría a partir de su experiencia en la lectura de cuentos tradicionales infantiles, poemas románticos leídos durante la adolescencia y acaso también libros de autoayuda o de contenido pseudo psicológico. Estas experiencias parecen no reconocer en muchos casos conexiones específicas y productivas con la construcción de su identidad como lector, como

5 Bas, Alcira. Los docentes como lectores. Cuadernillo de las Primeras Jornadas del Plan Nacional de Lectura. Región NEA: Ministerio de Cultura y Educación de la Provincia de Formosa, 2004. 
profesional o como adulto trabajador de la educación ni con el desarrollo de un proyecto cultural y no ponen como expectativas la actualización de las lecturas literarias. Otro grupo, formado por gran número de docentes, pese a haber leído mucho -libros de aventuras, colecciones de revistas de historietas, leyendas, biografías, poemas, libros históricos y periodísticos, poesías-, no se consideraba lector porque no había leído aquellos libros reconocidos como prestigiosos -por ejemplo los autores clásicos-, porque no lo había hecho sistemáticamente o porque en la actualidad no leía ficción. Este grupo era consciente y se planteaba relaciones posibles entre el trabajo docente y tarea de lector. Por último, un grupo muy pequeño de docentes había leído -y leía- autores y géneros variados para niños y adultos, estaba actualizado y había reflexionado acerca de la lectura de ficción y su incidencia en la construcción de una identidad lectora y lo que eso significa para los docentes como sujetos de la cultura y como educadores.
Este tipo de caracterización como cualquiera otra que podría realizarse a partir de experiencias de talleres con los maestros muestra la novedad de este modo de interrogar las prácticas culturales en la escuelas involucrando desde afuera a los sujetos de la institución y comprendiendo a la vez las condiciones en que esas prácticas son posibles (conflictos diversos, otros requerimientos dentro de la escuela, exceso de horas de trabajo, dificultades económicas para el acceso a los libros, entre otros). Los interrogantes continúan pues se trata de pensar en la incidencia de estas prácticas de lectura de los adultos a la hora de convertirse en mediadores de lectura en espacios escolares y de fuera de la escuela.

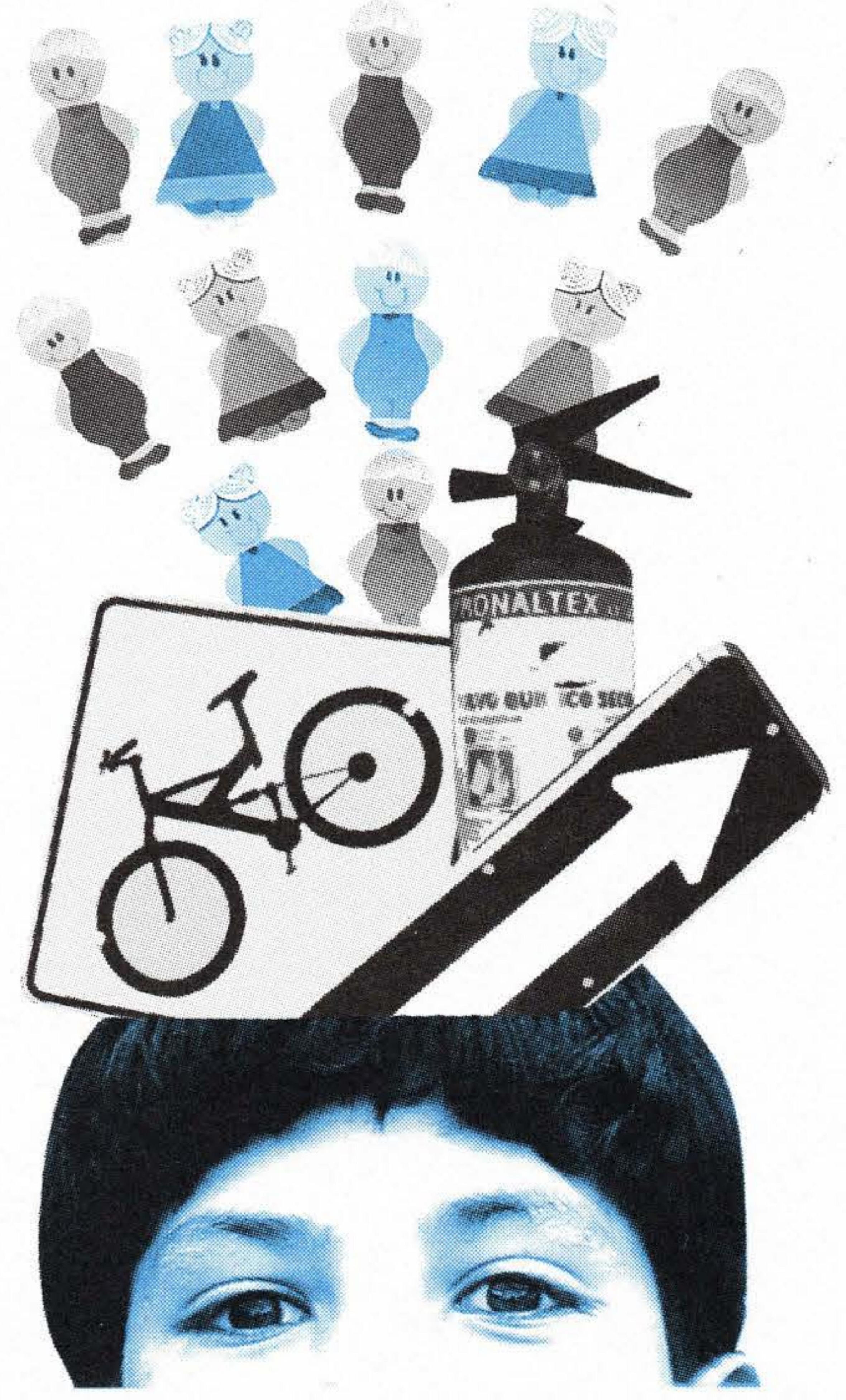


Otra línea de acción que apunta a reconocer las particulares idiosincrasias culturales en las que las prácticas de lectura se desarrollan y que intenta poner el acento en la necesidad de atender a estas particularidades como paso necesario éste trabajo es la denominada "Lectura en contextos de diversidad lingüística y cultural”. Se trata de una línea -desarrollada por la especialista Paola Iturrioz- que "parte del conocimiento y reconocimiento de la multiplicidad de escenarios, de la diversidad cultural presente en los distintos grupos en todo el país, sus modos de leer, y sus particulares acercamientos a los libros y apropiaciones de sentidos en diversas prácticas lectoras". Aquí la propuesta es a ese mapa de lectura que reconozca contextos de multilingüismo e interculturalidad: escuelas en comunidades aborígenes, en zonas de fronteras, escuelas rurales pero también escuelas de la periferia de las grandes ciudades en las que se escuchan, seguramente en el recreo, otras lenguas y los ecos de otras experiencias culturales. Contextos en los que se producen escenas que acaso nos descoloquen y afecten a nuestras representaciones acerca de la lectura y los modos de leer. Para ejemplificar, vale un testimonio recogido por Iturrioz en el que recupera la preocupación de un tallerista que estaba trabajando en la provincia de Misiones que daba cuenta del rechazo de padres de familia a la lectura de literatura puesto que consideraban que se perdía el tiempo, contando y leyendo historias "mentirosas" de animales que hablan. La desconfianza a la escritura y el "papel" -fundamentalmente cuando no puede ser descifrado- y, ciertas ideas acerca de la función de la escuela explicarían esta actitud de resistencia: para estos padres la escuela debe ser un espacio que trasmita conocimientos diferentes a los que se pueden adquirir en el hogar. En los relatos que los mayores narran a sus hijos -para entretener o enseñar conductas- también hay animales que hablan pero "la escuela" -dicen- "debería ocuparse de otros temas".

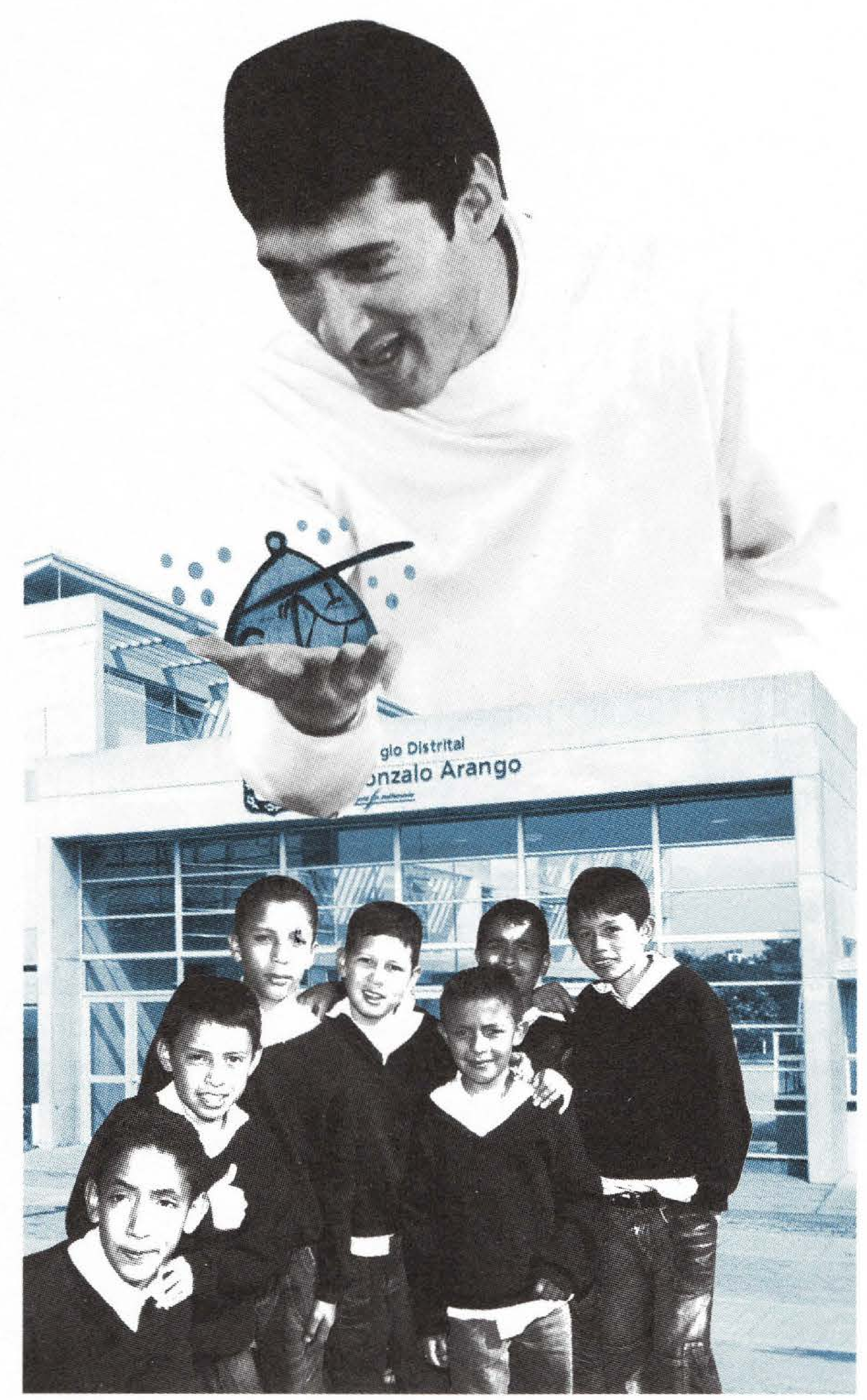

6 Iturrioz, Paola. "La lectura en contextos de diversidad lingüística y cultural", Cuadernillo de las Primeras Jornadas del Plan Nacional de Lectura. Región NEA: Ministerio de Cultura y Educación de la Provincia de Formosa, 2004. 
Tal como plantea Paola Iturrioz, trabajar en contextos de interculturalidad promueve complejizar las preguntas e imaginarse otras:

¿En qué sentidos la lectura ayuda en procesos de alfabetización en estos contextos signados por un alto índice de fracaso escolar, pobreza, marginalidad étnica, lingüística y cultural? ¿Cómo pensar la lectura más allá de la alfabetización inicial? ¿Cómo construir relaciones duraderas e intensas con la cultura escrita, el libro y la lectura en ámbitos en los que los años de escolarización no se extienden más que a la educación básica? ${ }^{7}$

Pensar en esta diversidad cultural como punto de partida para trabajar en prácticas de promoción de la lectura supone alargar la mirada más allá de la cotidianeidad escolar y supone el desafío de convertirse en un etnógrafo de la comunidad que circunda a la escuela. Traigo un ejemplo revelador de escenas posibles en que la lectura excede sus límites de contenido escolar. Se trata de una experiencia realizada por la profesora Cristina Blake -tallerista del Plan Nacional de Lectura- en una escuela de la periferia urbana de la ciudad de San Juan con un auditorio heterogéneo de unas cincuenta personas conformado por maestros, porteros, personal de cocina, directivos, bibliotecarios y padres de los niños discutiendo en torno a un cuento de Silvina Ocampo y a otro de la escritora de literatura para niños Graciela Cabal que los interpelaba desde la cuestión del miedo y cómo esas experiencias previas, literarias y de la vida, generaban una proliferación infinita de sentidos en construcción, de impresiones compartidas, de relaciones sorprendentes donde la llamada "comunidad educativa", sin que nadie haya faltado a la cita, compartía una experiencia cultural en el marco de la escuela.

7 Parte de esta propuesta se ha ido conformando con los informes que talleristas, escritores y narradores produjeron en el año 2001 en el marco del Plan Nacional de Lectura. En varias jurisdicciones del país, principalmente en escuelas de Misiones, Chaco, Santiago del Estero, Salta, Jujuy y Santa Cruz, con las características antes mencionadas, se llevaron a cabo talleres con los maestros y se trabajó con un corpus de 50 libros en un convenio con CERLAC-UNESCO. Desde los años 80 se está desarrollando en México un programa con los "Libros del Rincón” que articula, a su vez, con CERLAC-UNESCO. En convenio en el 2000 con el Plan Nacional de Lectura del Ministerio de Educación de la Nación a través del Programa "Podemos leer y escribir" se recibió esta dotación de 50 libros que, además, circula en otros países latinoamericanos. Esta acotada pero rica selección de libros incluía textos de difícil clasificación según criterios tradicionales. Uno de ellos enseñaba a hacer experimentos con las plantas en la cocina del hogar. Tampoco sirvieron de mucho mis anticipaciones respecto de los criterios con los cuales los participantes harían sus elecciones. Este libro, quizás sin la riqueza simbólica, retórica y semántica de la literatura, resultó una buena entrada para madres de la comunidad, una forma de acercamiento al objeto libro y una relación cercana con la bibliotecaria. 


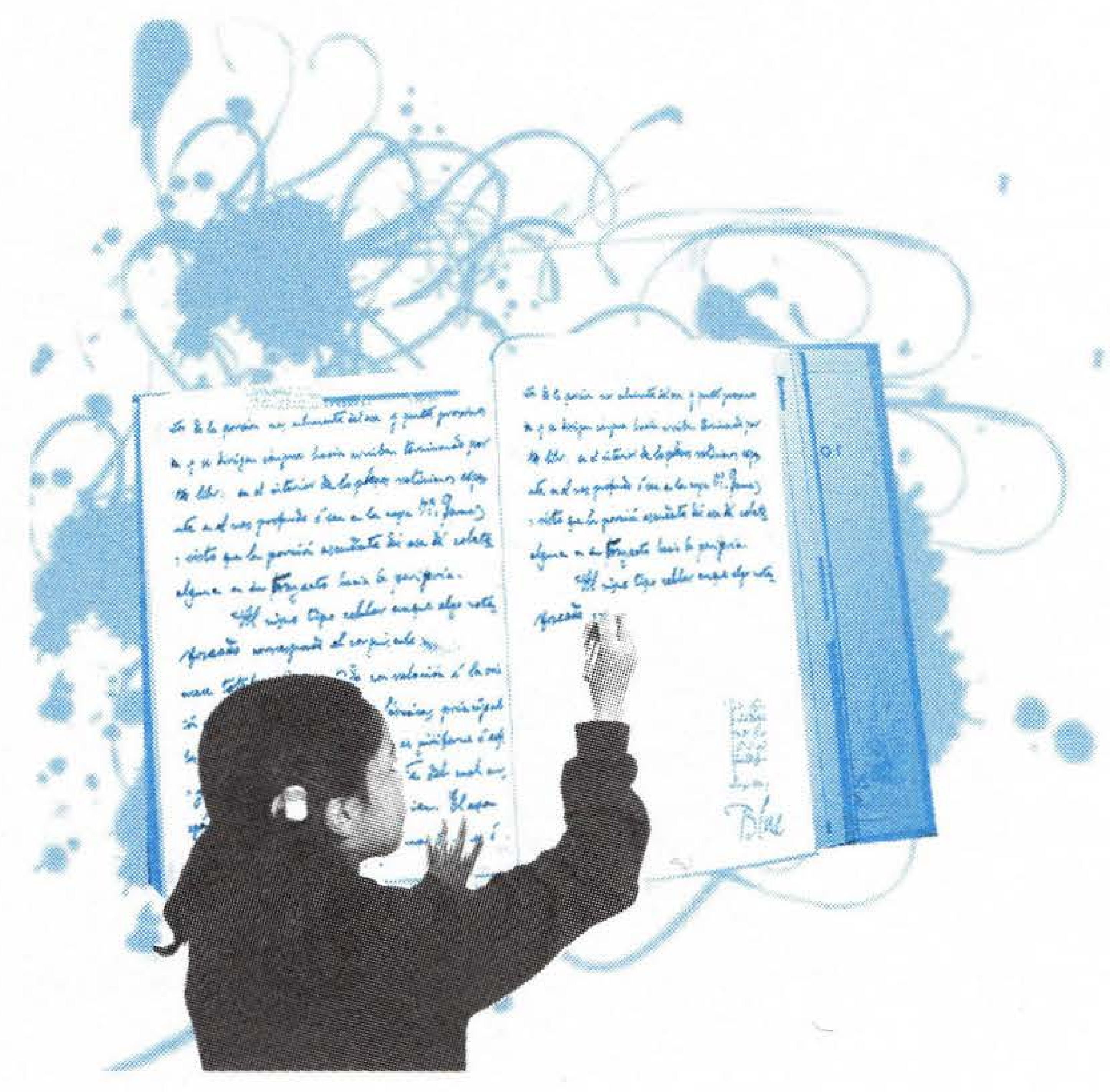

La lectura es una práctica cultural que se comparte, que desde la escuela se eyecta hacia el afuera de la escuela y ese entorno, más rico o más pobre en lecturas, enriquece y se enriquece con el intercambio con la escuela. Abuelos que cuentan cuentos en la escuela o niños que cuentan en otros espacios de la comunidad son algunas de las experiencias típicas que ratifican a la lectura como práctica potente, creadora de lazos sociales que son punto de partida en la construcción de nuevos lectores, en la creación de un contexto alfabetizador, es decir de un contexto propicio para el ingreso al mundo de la cultura escrita. Por eso trabajar con prácticas de promoción de la lectura en la escuela supone la construcción de redes que involucren a los más diversos sujetos que por fuera o por dentro de la escuela nos subrayan ese carácter sociocultural de la lectura. Por eso en algunas líneas de acción del Plan Nacional de Lectura en las provincias se incluyen a distintos sujetos de la comunidad que pueden desempeñarse como mediadores de lectura: bibliotecarios de bibliotecas populares, jubilados, actores y otros artistas, narradores, promotores sociales, beneficiarios de planes sociales para desempleados (entre ellos docentes), entre otros.
Otra línea en desarrollo vincula las prácticas de lectura con la oralidad como modalidad y estrategia de acceso a textos de la cultura escrita. Las experiencias de lectura compartida, en el aula o en otros espacios, la presencia de narradores profesionales o de escritores leyendo sus propios textos, propician situaciones habilitadoras de todas las personas que participan de estas experiencias. La lectura en voz alta y compartida permite la democratización de la audiencia porque aún los que no saben leer o lo hacen con dificultad participan del impacto que generan los textos, se dejan cautivar por las historias, escuchan atentamente cadencias, acentos, ritmos y metáforas. El texto que se presenta ahí en la oralidad no es el mismo texto escrito, aún cuando sea reproducido palabră por palabra se transforma en otro texto apenas entra en la escena de la narración. Quien narra reescribe el texto y quien escucha la narración lee esa totalidad de voz, palabras, cuerpo. Acordamos con Silvia Seoane ${ }^{8}$ cuando dice: "Hay mucho para explorar en las posibilidades verdaderamente democratizadoras de la oralidad desde el terreno de lo que habitualmente se llama promoción de la lectura".

8 Seoane, Silvia. "Narración oral y cultura escrita", Cuadernillo de las Primeras Jornadas del Plan Nacional de Lectura. Región NEA: Ministerio de Cultura y Educación de la Provincia de Formosa, 2004. 
Un último aspecto a considerar en lo que serían líneas específicas de acción responde a la necesidad de revalorizar de la dimensión material de la lectura, sin que esto sea visto como un gesto meramente complaciente de los gobiernos. Las experiencias muestran cómo es frente a un libro como objeto material específico con sus características de edición, diseño, ilustraciones, si la hubiere, es fundante de una relación interesante con la lectura. Tanto los especialistas del campo de la literatura infantil como ciertos didactas y pedagogos y junto con ellos los bibliotecarios vienen librando desde hace años una batalla a favor de la diversidad de libros en las prácticas de la lectura en la escuela, diversidad que permite la entrada al campo de la producción cultural, al conocimiento de la pluralidad de perspectivas y riqueza de información sobre un mismo tema. En nuestro país, la necesidad de reponer los objetos culturales, de que la escuela -en este caso a través de proyectos de promoción de la lectura- marque una diferencia cultural respecto de otras experiencias de los niños selección de libros constituye un objetivo fundamental de cualquier política que tenga a la igualdad educativa como horizontes.
Asegurado este marco podrán producirse las necesarias discusiones sobre criterios de selección, se podrán cotejar cánones, se pondrán en circulación nuevos autores o autores desconocidos, se propondrán recorridos lectores tanto de textos ficcionales como de textos informativos; en cualquier caso todo enunciado a favor de la lectura se convierte en consigna vacía, mera mueca de sus intenciones si no se ponen en juego libros, prácticas de gestión, experiencias pedagógicas, miradas críticas parecen conjugarse en la tarea de promover la lectura desde una agencia gubernamental. Como si camináramos sobre el peligroso filo que separa la burocracia de la literatura, los deseos de transformación de la inercia que resiste, la innovación de la rutina, las posibilidades de una sociedad con una tradición de lectores de las limitaciones de los tiempos que corren, la tarea de gestión supone un desafío permanente, un estar alerta inevitable. Se trata, en definitiva, de modos de recuperar las tensiones como parte de un pensamiento sobre las prácticas culturales y pedagógicas en su intrínseca complejidad. 


\section{Bibliografía}

AAVV. La enseñanza inicial de la lectura y la escritura en la Unión Europea. Madrid: Ministerio de Educación, Cultura y Deporte, 2002.

AAVV. La lectura en España. Informe 2002. José Antonio Millán (coordinador). Madrid: Federación de Gremios de Editores de España, 2002.

AAVV. Knowledge and skills for life. First results from Pisa 2000 (Programme for international student assessment). Education and skills, París: OECD, 2001.

Amado, Elba. "Leer es poder. Un estudio de las prácticas lectoras literarias de niños y jóvenes en contextos educativos no formales y populares de San Salvador de Jujuy”. Jujuy: Facultad de Humanidades y ciencias Sociales. Universidad Nacional de Jujuy, 2002.

Antezana, Luis. Teorías de la lectura. La Paz: Plural CESU, 1999.

Bahloul, Joel. Lecturas precarias. Estudio sociológico de los "poco lectores". México: Fondo de Cultura Económica, 2003.

Bas, Alcira. Los docentes como lectores. Cuadernillo de las Primeras Jornadas del Plan Nacional de Lectura, Región NEA. Ministerio de Cultura y Educación de la Provincia de Formosa, 2004.

Bolívar, Antonio y otros. La investigación biográfico-narrativa en educación. Madrid: La Muralla, 2001.

Bombini, Gustavo. Los arrabales de la literatura. La Historia de la enseñanza de la literatura en la escuela secundaria en la Argentina (1870-1960). (Tesis de Doctorado). Buenos Aires: Miño y Dávila y Facultad de Filosofía y Letras. Universidad de Buenos Aires, 2003.
Bombini, Gustavo. "La literatura en la escuela" en Alvarado, Maite (compiladora) Entre líneas. Buenos Aires: Manantial, 2001.

Bombini, Gustavo. "Sabemos poco acerca de la lectura" en Lenguas Vivas. Año 2, №2, Octubre-Noviembre. Buenos Aires: Instituto de Enseñanza Superior "Juan Ramón Fernández", 2002.

Bombini, Gustavo. "La lectura, una práctica posible", El Monitor. № ${ }^{\circ}$, $5^{\text {a }}$ Época, Octubre. Buenos Aires: Ministerio de Educación, Ciencia y Tecnología, 2004.

Bourdieu, Pierre. El sentido práctico, Madrid: Taurus, 1991.

Bourdieu, Pierre. Las reglas del arte (Especialmente Parte III: "Comprender el comprender"). Barcelona: Anagrama, 1992.

Cacérès, Geneviève. Regards neufs sur la lecture. Paris : Ed. Du Seuil, 1961.

Chartier, Anne-Marie: La lectura de un siglo a otro. Discursos sobre la lectura (1980-2000). Barcelona: Gedisa, 2002.

Connelly, Michael y Jean Clandinin. "Relatos de Experiencia e Investigación narrativa” en Larrosa, Jorge y otros: Déjame que te cuente, Ensayos sobre narrativa y educación. Barcelona, Laertes, 1995.

Cuesta, Carolina. "Hacia la construcción de una nueva mirada sobre los lectores y la lectura", en LuLú Coquette. Revista de Didáctica de la lengua y la literatura, Año 1, № 1 , Buenos Aires: Editorial El Hacedor, 2002.

Cuesta, Carolina. "Los diversos modos de leer literatura en la escuela: la lectura de textos literarios como práctica sociocultural". Tesis de Licenciatura dirigida por Dr. Gustavo Bombini. Facultad de Humanidades y Ciencias de la Educación. Universidad Nacional de La Plata, 2003. 
Gómez Soto, Ignacio. Mito y realidad de la lectura. Madrid: Endymon, 1999.

Iturrioz, Paola. "La lectura en contextos de diversidad lingüística y cultural", Cuadernillo de las Primeras Jornadas del Plan Nacional de Lectura, Región NEA. Ministerio de Cultura y Educación de la Provincia de Formosa, 2004.

Meek, Margaret. "¿Qué se considera evidencia en las teorías sobre literatura para niños?”, Theory into Practice, vol.XXI, $\mathrm{N}^{\circ} 4$, 1982. Traducido en: Un encuentro con la crítica y los libros para niños. Caracas: Parapara Clave. Banco del Libro, 2001.

Petit, Michele. Nuevos acercamientos entre la cultura y los jóvenes. México: Fondo de Cultura Económica, 1999.

Petit, Michele. Lecturas: del espacio íntimo al espacio privado. México: Fondo de Cultura Económica, 2001.

Privat, Jean-Marie. "Sociológicas de la didáctica de la lectura" en LuLú Coquette. Revista de Didáctica de la lengua y la literatura, Año 1, N¹, Buenos Aires: Editorial El hacedor, 2002.

Romero Brest, Gilda L. de. "Propuesta para una visión ampliada de la educación”, Bs. As., Cuadernos del CICE, 1987; y "Educación no Formal, Precisiones Terminológicas y Estrategias de Democratización”, Buenos Aires: Cuadernos del CICE, 1989.

Salvi, Alicia. "Recorridos lectores: el por qué, el para qué y el cómo", Cuadernillo de las Primeras Jornadas del Plan Nacional de Lectura, Región NEA. Ministerio de Cultura y Educación de la Provincia de Formosa, 2004.

Seoane, Silvia. "Narración oral y cultura escrita", Cuadernillo de las Primeras Jornadas del Plan Nacional de Lectura, Región NEA. Ministerio de Cultura y Educación de la Provincia de Formosa, 2004.
Cuesta, Carolina. "Los diversos modos de leer literatura en la escuela: la lectura de textos literarios como práctica sociocultural". Tesis de Licenciatura dirigida por Gustavo Bombini. Facultad de Humanidades y Ciencias de la Educación. Universidad Nacional de La Plata, 2003.

Gómez Soto, Ignacio. Mito y realidad de la lectura. Madrid. Endymon. 1999.

Iturrioz, Paola. "La lectura en contextos de diversidad lingüística y cultural", Cuadernillo de las Primeras Jornadas del Plan Nacional de Lectura, Región NEA. Ministerio de Cultura y Educación de la Provincia de Formosa, 2004.

Meek, Margaret. "¿Qué se considera evidencia en las teorías sobre literatura para niños?”, Theory into Practice, vol XXI, $N^{\circ} .4,1982$. Traducido en: Un encuentro con la crítica y los libros para niños. Caracas: Parapara Clave. Banco del Libro, 2001.

Petit, Michele. Nuevos acercamientos entre la cultura y los jóvenes. México: Fondo de Cultura Económica, 1999.

Petit, Michele. Lecturas: del espacio íntimo al espacio privado. México: Fondo de Cultura Económica, 2001

Privat, Jean-Marie. "Sociológicas de la didáctica de la lectura” en LuLú Coquette. Revista de Didáctica de la lengua y la literatura, Año 1, No1, Buenos Aires, Editorial El hacedor, 2002.

Romero Brest, Gilda L. de. "Propuesta para una visión ampliada de la educación”, Bs. As., Cuadernos del CICE, 1987; y "Educación no Formal, Precisiones Terminológicas y Estrategias de Democratización”, Bs. As., Cuadernos del CICE, 1989.

Salvi, Alicia. "Recorridos lectores: el por qué, el para qué y el cómo", Cuadernillo de las Primeras Jornadas del Plan Nacional de Lectura, Región NEA. Ministerio de Cultura y Educación de la Provincia de Formosa, 2004.

Seoane, Silvia. "Narración oral y cultura escrita", Cuadernillo de las Primeras Jornadas del Plan Nacional de Lectura, Región NEA. Ministerio de Cultura y Educación de la Provincia de Formosa, 2004. 